\title{
Enhancing chalcopyrite leaching by tetrachloroethylene-assisted removal of sulphur passivation and the mechanism of jarosite formation
}

Muhammet Kartal ${ }^{1}$, Fang Xia ${ }^{1, *}$, David Ralph ${ }^{1}$, William D. A. Rickard ${ }^{2}$, François Renard $^{3,4}$, Wei Li $^{5}$

${ }^{1}$ Discipline of Chemistry and Physics, College of Science, Health, Engineering and Education, Murdoch University, Perth, WA 6150, Australia

${ }^{2}$ John de Laeter Centre, Curtin University, Perth, WA 6845, Australia

${ }^{3}$ The Njord Centre, PGP, Department of Geosciences, University of Oslo, Oslo, Norway

${ }^{4}$ University Grenoble Alpes, University Savoie Mont Blanc, CNRS, IRD, IFSTTAR, ISTerre, 38000, Grenoble, France

${ }^{5}$ Department of Mechanical and Aerospace Engineering, West Virginia University, Morgantown, WV 26506, USA

Email address: fang.xia@murdoch.edu.au

\begin{abstract}
Chalcopyrite $\left(\mathrm{CuFeS}_{2}\right)$ is the primary ore mineral for copper, but leaching of this mineral under atmospheric conditions is slow due to the formation of surface passivating phases such as elemental sulphur and jarosite. Here, we studied chalcopyrite leaching in a sulphuric acid solution at $75{ }^{\circ} \mathrm{C}$ and $750 \mathrm{mV}$ (relative to the standard hydrogen electrode), and found that after adding $20 \mathrm{vol} \%$ of tetrachloroethylene (TCE) into the leaching solution, elemental sulphur was dissolved from chalcopyrite and surface passivation was removed at the early stage of leaching. The removal of surface sulphur significant enhanced the leaching rate by approximately $600 \%$ compared with TCE-free leaching. However, adding dimethyl sulfoxide (DMSO) did not improve the leaching rate. At the later stage of leaching, the increasing concentrations of $\mathrm{Fe}^{3+}$ from the dissolution of chalcopyrite and $\mathrm{K}^{+}$ possibly from the dissolution of minor amount of gangue minerals resulted in the precipitation of a potassium jarosite layer on the surface of chalcopyrite. The jarosite shell did not passivate TCE-free leaching due to its porous structure. However, in the case of leaching with TCE, elemental sulphur filled
\end{abstract}


the pores, and the jarosite shell became nearly impermeable, resulting in passivation after $80 \%$ copper extraction. This study demonstrates a way for effective removal of sulphur passivation at the early stage of chalcopyrite leaching by adding sulphur dissolving solvent such as TCE, but to prevent jarosite formation at the later stage of leaching, it is necessary to keep the concentrations of $\mathrm{Fe}^{3+}$ and $\mathrm{K}^{+}$at low levels.

Keywords: Chalcopyrite leaching; Sulphur passivation; Tetrachloroethylene; Jarosite passivation; FIBSEM tomography; XPS.

\section{Introduction}

Chalcopyrite $\left(\mathrm{CuFeS}_{2}\right)$ is the most abundant copper bearing mineral and the primary source for copper production ( $\mathrm{Li}$ et al., 2015b). While both pyrometallurgical and hydrometallurgical processes are technologically feasible for copper extraction from chalcopyrite, the pyrometallurgical processes predominate in the minerals industry (Debernardi and Carlesi, 2013; Watling, 2013). The shortage of high-grade deposits and the increasing environmental concerns of pyrometallurgical processing have encouraged efforts for low-cost and more environmentally friendly hydrometallurgical leaching processing, ideally, aqueous oxidation at atmospheric pressure (Aydogan et al., 2005; Harmer et al., 2006; Hidalgo et al., 2018; Mudd, 2010; Watling, 2006).

The foremost challenge to chalcopyrite leaching under atmospheric pressure conditions is the slow kinetics. Crundwell (1988) proposed that, fundamentally, the charge transfer between the solution redox couple and the conduction or valence band of chalcopyrite is essential for chalcopyrite leaching. However, leaching of chalcopyrite often produces secondary phases covering the surface, blocking direct contract between solution and chalcopyrite surface and impeding efficient charge transfer. This phenomenon is called surface passivation (Debernardi and Carlesi, 2013) and has been the subject of many studies (Córdoba et al., 2008; Li et al., 2010; Nikkhou et al., 2019; Stott et al., 2000)though there is no consensus on the mechanisms of this passivation. The commonly proposed mechanisms are precipitation of metal-deficient sulphides, polysulphides, elemental sulphur, and jarosites (potassium, sodium, hydronium), with elemental sulphur and jarosites the dominant phases (Ahn et al., 2019; Klauber, 2008). 
Several methods have been reported for removing or reducing elemental sulphur surface passivation, including enhancing the porosity of the sulphur layer by galvanic coupling between pyrite and chalcopyrite (Dixon et al., 2008; Nazari et al., 2012a; Nazari et al., 2012b), enhancing the porosity and electrical conductivity of the sulphur layer by adding silver ions as a catalyst (Nazari et al., 2012a; Nazari et al., 2012b), heating to temperatures higher than the melting point of sulphur $\left(115.2{ }^{\circ} \mathrm{C}\right)$ in high-pressure leaching (Jorjani and Ghahreman, 2017), leaching at high pH (e.g., ammoniacal leaching) outside the stability region of sulphur (Reilly and Scott, 1977), ultrafine grinding to less than $10 \mu \mathrm{m}$ so that chalcopyrite grains are leached before passivation occurs (Baláž, 2008), and peeling off sulphur by either sonochemical leaching in which ultrasound causes surface disruption (Abed, 2002), or microwave assisted leaching in which the large thermal convection currents due to temperature difference between the solution and the solid phases agitate sulphur particles at the surface (Weian, 1997). These methods enhanced chalcopyrite leaching, but are either expensive (pressure leaching, ultrafine grinding, silver catalyst), small scale (ultrasound bath, microwave), require the addition of large amounts of pyrite (galvanic coupling), or affected by evaporative loss of ammonia (ammoniacal leaching).

Another method for removing sulphur passivation involves adding sulphur-dissolving nonpolar solvents. Havlik and Kammel (1995) added carbon tetrachloride $\left(\mathrm{CCl}_{4}\right)$ into the leaching solution (1.0 $\mathrm{M} \mathrm{FeCl}_{3}+0.2 \mathrm{M} \mathrm{HCl}$ ) and observed no sulphur on leached chalcopyrite particles, most likely due to the high sulphur solubility in $\mathrm{CCl}_{4}, 13.2 \mathrm{~g} \mathrm{~L}^{-1}$ at $25^{\circ} \mathrm{C}$. The rate of leaching was enhanced by nearly $100 \%$ when compared with their $\mathrm{CCl}_{4}$-free experiments, but the high toxicity of $\mathrm{CCl}_{4}$ restricts its use in the industry. Another nonpolar but low toxicity sulphur-dissolving solvent is tetrachloroethylene (TCE), $\mathrm{C}_{2} \mathrm{Cl}_{4}$, which has a higher sulphur solubility of $24.79 \mathrm{~g} \mathrm{~L}^{-1}$ at $25^{\circ} \mathrm{C}$ (Seidell and Linke, 1941). TCE has been demonstrated as an effective sulphur-removal agent in sphalerite leaching (Peng et al., 2011; Peng et al., 2005), yet its effectiveness in chalcopyrite leaching has not been studied previously.

Researchers have also studied the effect of polar solvents on chalcopyrite leaching and reported enhanced leaching after adding acetone (Solis-Marcíal and Lapidus, 2013), or ethylene glycol (Jorjani and Ghahreman, 2017; Mahajan et al., 2007; Solis-Marcíal and Lapidus, 2013). These solvents have much low sulphur solubilities, and their effectiveness in enhancing chalcopyrite leaching has been 
attributed to their role in preventing the decomposition of the oxidising agent hydrogen peroxide rather than removing sulphur from the grain surface (Jorjani and Ghahreman, 2017; Mahajan et al., 2007). However, their use under the industrial context is challenging since acetone has fire and explosion hazards due to its highly evaporative and flammable nature; ethylene glycol is also highly toxic. A much safer polar solvent is dimethyl sulfoxide (DMSO) as it is non-toxic and has a low vapour pressure (0.6 $\mathrm{mmHg}$ ) under ambient conditions, yet its effectiveness in chalcopyrite leaching has not been reported in the literature.

The aim of this work is to investigate the effectiveness of a nonpolar solvent TCE and a polar solvent DMSO in enhancing atmospheric leaching of chalcopyrite, using hydrogen peroxide as the oxidant and sulphuric acid as the leaching solution. We conducted a direct comparison of leaching experiments carried out under conditions with and without TCE and DMSO. A key feature of this study is a detailed characterization of the solid residue by quantitative phase analyses to obtain the abundances of secondary phases, scanning electron microscopy (SEM) and energy dispersive spectroscopy (EDS) to identify and locate these secondary phases, X-ray photoelectron spectroscopy (XPS) to detect surface species, and focused ion beam-SEM tomography to determine the porosity distributions in secondary jarosite at high spatial resolution. The leaching rate was assessed under various conditions, and the mechanisms are investigated.

\section{Materials and methods}

\subsection{Materials}

A high-grade massive chalcopyrite specimen from Wallaroo Mines, South Australia, was used in the leaching experiments. The specimen was crushed and sieved to obtain a size fraction of 38-75 $\mu \mathrm{m}$. A portion of the sample was digested in acid and analysed by an inductively coupled plasma-mass spectrometer (ICP-MS) for the major and minor metallic elements. The results show that the molar ratio of $\mathrm{Cu} / \mathrm{Fe}$ is 1.02 (Table 1), suggesting a composition very close to stoichiometric chalcopyrite $\mathrm{CuFeS}_{2}$. Synchrotron-based powder X-ray diffraction (PXRD) and Rietveld-based quantitative phase analysis show that the specimen contains $98.9 \pm 0.1 \mathrm{wt} . \%$ of chalcopyrite and $1.1 \pm 0.1 \mathrm{wt} . \%$ of pyrite, and the chalcopyrite has a tetragonal unit cell with $a=b=5.2995 \AA$ and $c=10.4236 \AA$ (Fig. 1a, details in section 
2.3.3). From scanning electron microscopy (SEM) images, the chalcopyrite grains have a smooth surface with ultrafine particles scattered on the surface and initial $\mu \mathrm{m}$-scale porosity was observed inside the grains (Fig. 1b, 1c).

Deionised water was used in solution preparation. Chemicals used include $\mathrm{H}_{2} \mathrm{SO}_{4}(95 \%$, VWR), TCE ( $\geq 99.0 \%$, Sigma-Aldrich), DMSO (99.9\%, Chem-Supply), $\mathrm{H}_{2} \mathrm{O}_{2}$ (30\% w/v, Rowe Scientific) and elemental sulphur powder (99.3\%, Ajax).

\subsection{Leaching experiments}

Leaching experiments were carried out in custom-built jacketed glass reactors (1.0 L capacity) (Fig. 2). Each reactor was sealed with a five-port lid for housing a thermometer, a two-blade PTFE impeller, a high-temperature $\mathrm{E}_{\mathrm{h}}$ probe, a hydrogen peroxide inlet, and a reflux condenser. The temperature in the reactor was maintained at $75{ }^{\circ} \mathrm{C}$ with an accuracy of $\pm 1{ }^{\circ} \mathrm{C}$ by circulating hot water through the jacket. The hot water was supplied by a thermostatically-controlled water bath. In each experiment, $500 \mathrm{~mL}$ of solution was first heated to $75{ }^{\circ} \mathrm{C}$, and then $2.0 \mathrm{~g}$ of chalcopyrite was added to start leaching. Homogenous mixing was maintained by agitation at a speed of $250 \mathrm{rpm} . \mathrm{E}_{\mathrm{h}}$ values were measured using a Pt electrode with $\mathrm{Ag} / \mathrm{AgCl}$ reference, which was calibrated using an oxidation-reduction potential standard solution (ORP, $475 \mathrm{mV}$, ThermoFisher). All $\mathrm{E}_{\mathrm{h}}$ values reported in this paper are relative to the standard hydrogen electrode (SHE). Throughout the leaching experiments, $\mathrm{E}_{\mathrm{h}}$ of the solution was maintained at $750 \mathrm{mV}$ by pumping a $0.735 \mathrm{M} \mathrm{H}_{2} \mathrm{O}_{2}$ solution into the reactor using a peristaltic pump whenever $\mathrm{E}_{\mathrm{h}}$ dropped below $750 \mathrm{mV}$. Four leaching experiments were carried out to study the effect of TCE and DMSO on chalcopyrite leaching, including one experiment using $500 \mathrm{~mL}$ of $0.05 \mathrm{M} \mathrm{H}_{2} \mathrm{SO}_{4}$ solution ( $\mathrm{pH} 1.25$ ), one experiment using $450 \mathrm{~mL}$ of $0.05 \mathrm{M} \mathrm{H}_{2} \mathrm{SO}_{4}$ solution and $50 \mathrm{~mL}$ of TCE, one experiment using $400 \mathrm{~mL}$ of $0.05 \mathrm{M} \mathrm{H}_{2} \mathrm{SO}_{4}$ solution and $100 \mathrm{~mL}$ of TCE, and one experiment using $450 \mathrm{~mL}$ of $0.05 \mathrm{M} \mathrm{H}_{2} \mathrm{SO}_{4}$ solution and $50 \mathrm{~mL}$ of DMSO. These experiments are denoted as 'solvent free', TCE10, TCE20, and DMSO10, respectively.

The leaching solutions were sampled $(2.0 \mathrm{~mL})$ periodically from the top of the leaching solution with the agitation temporary turned off. For TCE experiments, samples were taken after TCE settlement to the bottom of the reactor (TCE is heavier than water and is immiscible). After cooling to room 
temperature, the $\mathrm{pH}$ was measured using a Eutech $\mathrm{pH} 2700$ benchtop $\mathrm{pH}$ meter. For selected sampling events, a small amount of solid residue was also taken from the bottom of the reactor. The solid samples were washed with deionised water and dried at room temperature for further analyses. After each sampling, the leaching solutions were topped up to the initial volume and initial solvent content by using $0.05 \mathrm{M} \mathrm{H}_{2} \mathrm{SO}_{4}, 10$ vol\% DMSO in $0.05 \mathrm{M} \mathrm{H}_{2} \mathrm{SO}_{4}$, and TCE.

\subsection{Fluid and solid samples characterisation}

\subsubsection{ICP-MS}

The solution samples were filtered (Millex-GP syringe filter, $0.22 \mu \mathrm{m}$ polyethersulfone membrane) before they were analysed for $\mathrm{Cu}$ and $\mathrm{Fe}$ concentrations by an inductively coupled plasma-mass spectrometer (ICP-MS) using a ThermoFisher Scientific iCAP Q Series spectrometer plus a CETAC ASX520 Autosampler. An 8-point calibration was set for the calibration curve (blank, 1, 5, 10, 50, 100, $200,500 \mathrm{ppb}$ ) and recalibrations were applied after every five readings by using the $10 \mathrm{ppb}$ standard solution. Samples were diluted by a factor of either 2500 or 3000 times to bring the readings within the calibration ranges. Each sample was measured five times, and the mean value is reported in the present study.

\subsubsection{SEM-EDS}

A Zeiss Neon 40EsB field emission scanning electron microscope (SEM) equipped with an energy dispersive spectrometer (EDS) was used for SEM-EDS examinations. Electron micrographs of particle surfaces and cross-sections were taken under secondary electron (SE) or backscattered electron (BSE) modes. For cross-section examinations, particles were embedded into epoxy resin, ground by 1200 grit silicon carbide abrasive papers, and then polished using $3 \mu \mathrm{m}$ and $1 \mu \mathrm{m}$ diamond suspensions. After surface cleaning and drying, the resin blocks were coated with a thin carbon film to increase conductivity. Micrographs were taken using an accelerating voltage of either 15 or $20 \mathrm{kV}$. For EDS analyses, the acquisition time was set to 120 seconds.

\subsubsection{PXRD}


The unleached chalcopyrite was analysed by synchrotron-based high-resolution powder X-ray diffraction (PXRD) at the Australian Synchrotron powder diffraction beamline. The X-ray wavelength (0.590928 $\AA$ ) and zero shift were calibrated by a $\mathrm{LaB}_{6}$ standard (NIST SRM 660b). The ground powder sample was loaded into a glass capillary with an outer diameter of $0.7 \mathrm{~mm}$ and a wall thickness of 0.01 $\mathrm{mm}$. The diffraction pattern was collected over a 2-theta range of $1.5-70^{\circ}$, using a high-resolution Mythen detector under the Debye-Scherrer geometry.

The leached samples were analysed by laboratory-based PXRD, using a Bruker D8 Advance diffractometer equipped with a copper tube $(\lambda=1.5418 \AA, 40 \mathrm{kV}, 40 \mathrm{~mA})$ and a LynxEye detector. In a typical data collection, $20-30 \mathrm{mg}$ of sample was ground in an agate mortar in ethanol and then the powder was spread uniformly on a silicon 'zero-background' sample holder. After ethanol evaporation, the sample was exposed to X-ray for data acquisition over the $2 \theta$ range $5-135^{\circ}$ with a step size of $0.02^{\circ}$ and an acquisition duration of $1.2 \mathrm{~s}$ per step.

Diffraction patterns were analysed by Rietveld refinement (Rietveld, 1969), using TOPAS Academic v6.0 software, to determine the unit cell parameters and quantitative phase fractions (Hill and Howard, 1987). In each refinement, the background and scale factors were refined first, followed by unit cell parameters, and finally peak-shape parameters. The background was modelled using a fifth order polynomial function and the peak shape using a pseudo-Voigt function that considers both Gaussian and Lorentzian convolutions. The initial structural models of the mineral phases were taken from the COD and ICSD databases: COD 96-901-5637 for chalcopyrite (Knight et al., 2011), COD 96-900-9286 for jarosite (Menchetti, 1976), ICSD 27261 for sulphur (S 8 (Pawley and Rinaldi, 1972). Once good refinement was achieved, as indicated by low values of the weighted-profile $R$-value $R_{w p}$ and goodness of fit $\chi^{2}$ (McCusker et al., 1999), the weight percentages of the involved phases were calculated by,

$$
W_{p}=(S Z M V)_{p} / \Sigma_{i}(S Z M V)_{i}
$$

where $W_{p}$ is the relative weight percentage of phase $p, S$ the scale factor, $Z$ the number of formula units per unit cell, $M$ the molecular weight of the formula unit, and $V$ the volume of the unit cell. $i$ represents each phase in the mixture. 


\subsubsection{XPS}

X-ray photoelectron spectroscopy (XPS) analyses were carried out by using a Kratos AXIS Ultra DLD instrument, under a vacuum of $4 \times 10^{-9}$ Torr. Monochromatic aluminium Ka X-ray running at $225 \mathrm{~W}$ with a characteristic energy of $1486.6 \mathrm{eV}$ was applied. Pass energies of $160 \mathrm{eV}$ and $20 \mathrm{eV}$ were used for survey and high-resolution scans, respectively. The electron take-off angle was normal to the sample surface. Sputtering treatment was not conducted to remove surface oxidation layer. The charge neutraliser, providing low energy electrons to enable a uniform surface potential, was utilised to compensate for surface static charging resulting from X-ray photoemission. The analysis depth was less than $15 \mathrm{~nm}$ into the surface of the sample, and the analysis area (Iris aperture) was set to $300 \times 700 \mu \mathrm{m}$, covering dozens of grains. Sample cooling was not available during the measurement.

The XPS data were analysed using CasaXPS software version 2.16 (Fairley et al., 2005). The fitting of the high-resolution spectra of $\mathrm{S} 2 \mathrm{p}$ and $\mathrm{O}$ 1s were performed using a peak profile function with $70 \%$ Gaussian and 30\% Lorentzian contributions on a Shirley background (Sandström et al., 2005; Shirley, 1972; Yang et al., 2015a). For the spectrum of S 2p of the unleached chalcopyrite, the Shirley function failed to fit the background and instead the background was modelled using a Tougaard type function. The $\mathrm{C} 1 \mathrm{~s}$ spectrum of the mineral mixture is composed of three peaks at: $286.4 \mathrm{eV}, 286.1 \mathrm{eV}$ and 288.5 $\mathrm{eV}$ which were assigned to $\mathrm{C}-\mathrm{C} / \mathrm{C}-\mathrm{H}, \mathrm{C}-\mathrm{O}$ and $\mathrm{C}=\mathrm{O}$, respectively (Greczynski and Hultman, 2017). The $\mathrm{C}-\mathrm{C} / \mathrm{C}-\mathrm{H}$ peak at $286.4 \mathrm{eV}$ was used for calibrating the binding energy scale of the entire XPS spectra (Khmeleva et al., 2005; Zhao et al., 2015). For fitting of the $\mathrm{S} 2 \mathrm{p}$ component pairs, a peak area ratio of $2: 1$ for $2 \mathrm{p}_{3 / 2}: 2 \mathrm{p}_{1 / 2}$ was used, the difference of binding energy between $2 \mathrm{p}_{3 / 2}$ and $2 \mathrm{p}_{1 / 2}$ was set to $1.2 \mathrm{eV}$, and the full width at half maximum (FWHM) of the pair was set to identical values.

\subsubsection{FIB-SEM tomography}

A Tescan Lyra3 focused ion beam-scanning electron microscope (FIB-SEM) was used for the 3D tomographic analysis using the slice and view method. A region of interest ( $15 \mu \mathrm{m}$ sided cube) was prepared for analysis by removing surrounding material and coating with a protective layer of ion beam deposited Pt. $\mathrm{A} \mathrm{Ga}^{+}$ion beam at $30 \mathrm{kV}$ and $1 \mathrm{nA}$ was used to remove $50 \mathrm{~nm}$ thick slices of material. After the removal of each layer, SE and BSE images were taken with a lateral pixel size of $25 \mathrm{~nm}$. A 
typical dataset consisted of more than 200 slices. The 3D model, with a voxel size of $25 \times 25 \times 50 \mathrm{~nm}^{3}$, was reconstructed from the images using Avizo software (version 9.5, FEI, US). The procedure of FIBSEM slice and view analysis is shown in Fig. 3.

\subsection{Determination of sulphur solubility in TCE and DMSO}

Sulphur solubilities in TCE and DMSO at $75{ }^{\circ} \mathrm{C}$ were measured using commercial sulphur powder that has the same crystal structure ( $\mathrm{S}_{8}$; orthorhombic; space group: $\left.F d d d\right)$ as the sulphur produced from the leaching experiments. The sulphur powder was ground to finer particles $(<5 \mu \mathrm{m})$ prior to use to accelerate dissolution. Four grams of sulphur was mixed with $25 \mathrm{~mL}$ TCE or 1 gram of sulphur was mixed with $25 \mathrm{~mL}$ DMSO, both in a $30 \mathrm{~mL}$ Schott glass bottle. The glass bottles were sealed and placed in a circulated water bath maintained at $75{ }^{\circ} \mathrm{C}\left( \pm 0.1^{\circ} \mathrm{C}\right)$ for 14 days. Based on an early study on the determination of sulphur solubilities in organic solvents, equilibrium is normally reached within $12 \mathrm{~h}$ (Ren et al., 2011). Hence, 14 days should be sufficient to reach equilibrium. After dissolution, the mixtures were filtered at $75^{\circ} \mathrm{C}$, and the undissolved sulphur residues were rinsed by Milli-Q water (40 $\mathrm{mL} \times 10$ times) to remove residue solvent (especially the miscible DMSO) from sulphur. Then, the residue sulphur was dried and the masses were weighed. Finally, the dissolved amount was calculated based on the difference between initial and final mass, and the solubilities $\left(\mathrm{g} \mathrm{L}^{-1}\right)$ were determined based on dissolved mass and the solvent volume.

\subsection{Thermodynamic analysis and reaction modelling}

The plotting of Eh-pH diagrams and numerical modelling of the reactions were carried out using GWB software package (v.11) with the database 'thermo.com.V8.R6+.tdat'.

\section{Results}

\subsection{Extraction curves}

Extraction curves of $\mathrm{Cu}$ and $\mathrm{Fe}$ for leaching experiments without added organic solvent (denoted as solvent-free), those where 10 and $20 \% \mathrm{v} / \mathrm{v}$ TCE were added (denoted as TCE10 and TCE20 respectively) and where $10 \%$ v/v DMSO was added (denoted as DMSO10) are presented in Fig. 4. 
Extractions were expressed as the percentages of dissolved $\mathrm{Cu}$ and $\mathrm{Fe}$ of the total amount present in the chalcopyrite mineral before leaching.

Copper dissolution from the mineral was rapid in the experiments containing TCE compared with DMSO10 and solvent-free experiments (Fig. 4a). For example, over a period of 80 h, the TCE20 and TCE10 experiments released $75 \%$ and $40 \%$ of the total available copper into solution, respectively. This compares with only $12 \%$ from the solvent-free experiment, and $8 \%$ from the DMSO10 experiment. These results demonstrate that adding $20 \% \mathrm{v} / \mathrm{v}$ TCE resulted in a 6 -fold increase in leaching rate but adding DMSO did not improve leaching.

The appearance of $\mathrm{Fe}$ in the leaching solution initially followed a similar pattern as $\mathrm{Cu}$, but relatively lower Fe extractions were observed at the later stages (Fig. 4b). This is because solution concentrations represent the net result of leaching from the mineral and the precipitation of solid $\mathrm{Fe}(\mathrm{III})$ phases at the later stages.

\subsection{Phase analysis}

PXRD phase identification and quantitative phase analyses were carried out for residues leached without solvent and using DMSO and TCE. Fig. 5 shows the data obtained from solvent-free (at 148 and $500 \mathrm{~h}$ ), TCE10 (at $304 \mathrm{~h}$ ), TCE20 (at $218 \mathrm{~h}$ ), and DMSO10 (at $237 \mathrm{~h}$ ) experiments. The results show that sulphur was almost completely removed from the grains when TCE was used as an additive. No sulphur was detected in residues from TCE10, and only $2.7 \mathrm{wt} . \%$ was found in the TCE20 sample. The solvent-free experiment at $500 \mathrm{~h}$ reported $15.8 \mathrm{wt} . \%$ sulphur, while the DMSO10 experiment showed 9.8 wt.\%. All experiments at later stages showed significant jarosite solids as the major reaction product, but jarosite was not observed at the early stages, including DMSO10 (at $237 \mathrm{~h}$ ) and solventfree (at $148 \mathrm{~h}$ ). The formation of jarosite at the later stages coincides with the drop of iron in the extraction curves of Fig. 4b, suggesting the scavenging of dissolved iron by jarosite precipitation.

\subsection{Microstructural analysis}

Microanalysis by EDS was conducted on both powder and cross-sectional surfaces of the leached samples from the solvent-free experiment at 148 and 500 hours, the TCE10 experiment at 116 and 304 
hours, the TCE20 experiment at 90 and 218 hours, and the DMSO10 experiment at 237 hours. Phases in the SEM micrographs are labelled based on compositional analysis by EDS.

The solvent free leaching experiment showed some solid sulphur on particle surfaces after 148 hours (Fig. 6a). Cross sections showed cracks and pores within the particles (Fig. 6b). After $500 \mathrm{~h}$, the surface of the particles exhibited rough topography (Fig. 6c), and the cross-sections of the particles revealed shells of jarosite surrounding small chalcopyrite cores (Fig. 6d). elemental sulphur patches were found on the surface of the chalcopyrite core (Fig. 6d inset). For experiments TCE10 and TCE20, jarosite precipitation was very significant, especially at the later stage of leaching (Figs. 7c, 7d, 8c, 9d). For the DMSO10 experiment, sulphur was observed on the surface of the chalcopyrite particles (Fig. 9), but no jarosite phase was evident.

\subsection{D microstructure of leached chalcopyrite rims}

FIB-SEM-tomography analyses were conducted on the shells of leached mineral grains from the solvent-free $(500 \mathrm{~h})$ and TCE20 $(218 \mathrm{~h})$ experiments. For the solvent-free grain, the shell was porous with a total porosity of about $0.7 \%$ (Fig. 10a). The analysed volume contained 72 pores, and their pore volume ranged from $3.0 \times 10^{5}$ to $1.3 \times 10^{7} \mathrm{~nm}^{3}$ (Fig. 11), or diameter ranged from 83 to $292 \mathrm{~nm}$ (assuming a spherical shape). No holes were observed on the shell. For the TCE20 grain, no obvious porosity was detected, but there existed a few holes on the shell (Fig. 10b). Elemental sulphur particles were embedded in the jarosite shell with some of them also exposed on the outer surface of the shell. Videos of these $3 \mathrm{D}$ reconstructions are provided in the supporting information.

\subsection{Particle surface analysis}

In order to understand the evolution of the surface species, XPS spectra were collected on the unleached chalcopyrite, and on the leached samples from the solvent-free experiment at $148 \mathrm{~h}$ and $500 \mathrm{~h}$, and from the TCE20 experiment at $218 \mathrm{~h}$. The unleached chalcopyrite sample was prepared by crushing chalcopyrite and then leaving the sample in air under ambient condition for a few days without protection from oxidation and control of humidity. This is to reveal surface oxidation of unleached chalcopyrite under ambient condition which is also experienced in the leaching experiments and in the 
industrial processing. The survey spectra of the 4 samples revealed the quantity of each of the detected elements $(\mathrm{Cu}, \mathrm{Fe}, \mathrm{S}, \mathrm{O}$, and $\mathrm{K})$ and their atomic percentages are summarized in Table 2. Although $\mathrm{Na}$ was detected as a minor element (3.58 wt.\%) by ICP-MS (Table 1), the survey spectra did not show this element. Note that because a cooling stage was not available during measurement the percentage of elemental sulphur is likely underestimated due to the possible evaporation/sublimation loss of sulphur under high vacuum (Harmer et al., 2006; Kartio et al., 1992). However, elemental sulphur was detected in other XPS studies without a cooling stage (e.g., Hackl et al., 1995; Nava et al., 2008; Khmeleva et al., 2005). High resolution XPS spectra of $\mathrm{Cu} 2 \mathrm{p}, \mathrm{Fe} 2 \mathrm{p}, \mathrm{S} 2 \mathrm{p}, \mathrm{K} 2 \mathrm{p}$, and $\mathrm{O} 1 \mathrm{~s}$ of the 4 samples were collected and are presented in Fig. 12. The $\mathrm{S} 2 \mathrm{p}$ and $\mathrm{O} 1 \mathrm{~s}$ spectra were fit and the quantified results are summarized in Table 3 and Table 4, respectively. The XPS results of each sample are described below. The unleached chalcopyrite contained 17 at. $\% \mathrm{Cu}, 14$ at. $\% \mathrm{Fe}, 57$ at. $\% \mathrm{~S}$ and 13 at. $\% \mathrm{O}$ (Table 2). The $\mathrm{Cu} 2 \mathrm{p}$ spectrum displays two strong peaks at $2 \mathrm{p}_{3 / 2}$ (Fig. 12a); one peak at $932.1 \mathrm{eV}$ suggesting the presence of $\mathrm{Cu}(\mathrm{I})-\mathrm{S}$ (Nava et al., 2008; Wang et al., 2016; Zhao et al., 2015); considering the presence of Fe(III)-S at $708.3 \mathrm{eV}$ in the Fe 2p spectrum (Fig. 12b) (Brion, 1980), and the bulk $\mathrm{S}^{2-}$ peak at 161.1 $\mathrm{eV}$ in the $\mathrm{S} 2 \mathrm{p}$ spectrum (Fig. 12c) (Li et al., 2015a; Li et al., 2015b; Li et al., 2016), we confirm the presence of chalcopyrite. The other peak in the $\mathrm{Cu} 2 \mathrm{p}$ spectrum at $934.6 \mathrm{eV}$ (Fig. 12a) could be assigned to $\mathrm{Cu}(\mathrm{II})-\mathrm{O}, \mathrm{Cu}(\mathrm{II})-\mathrm{OH}$, or $\mathrm{Cu}(\mathrm{II})-\mathrm{SO}$, since the binding energies of these species are very close (Harmer et al., 2006; Klein et al., 1983; Li et al., 2015b; Parmigiani et al., 1992; Wang et al., 2016). Considering the presence of $\mathrm{SO}_{4}{ }^{2-}$ in the $\mathrm{S} 2 \mathrm{p}$ spectrum (Fig. 12c; Table 3) (Harmer et al., 2006), and the presence $\mathrm{O}^{2-}, \mathrm{OH}^{-}$and $\mathrm{H}_{2} \mathrm{O}$ in the $\mathrm{O}$ 1s spectrum (Fig. 12e) (Li et al., 2015b; Nesbitt and Muir, 1998; Knipe et al., 1995), the most likely oxidised form of copper included $\mathrm{CuO}, \mathrm{Cu}(\mathrm{OH})_{2}$, and $\mathrm{CuSO}_{4} \cdot 5 \mathrm{H}_{2} \mathrm{O}$. In the Fe 2p spectrum (Fig. 12b), apart from the Fe(III)-S peak, the other broad peak at 711-714 eV could be assigned to $\mathrm{Fe}(\mathrm{III})-\mathrm{O} / \mathrm{OH}$ or $\mathrm{Fe}(\mathrm{III})-\mathrm{SO}$ species. This is because $711-712 \mathrm{eV}$ is indicative of $\mathrm{Fe}(\mathrm{III})-$ $\mathrm{O} / \mathrm{OH}$ species (Acres et al., 2010b; Li et al., 2016) and 710-714 eV is indicative of Fe(III)-SO species (Buckley and Woods, 1984; Fairthorne et al., 1997; Li et al., 2014; McIntyre and Zetaruk, 1977; Wu et al., 2019). Similarly, considering the sulphur and oxygen species (Fig. 12c and e), the likely oxidized forms of iron were $\alpha-\mathrm{FeOOH}$ and $\mathrm{Fe}_{2}\left(\mathrm{SO}_{4}\right)_{3} \cdot \mathrm{xH}_{2} \mathrm{O}$ (Brion, 1980; Suyantara et al., 2018). In the $\mathrm{S} 2 \mathrm{p}$ 
spectrum (Fig. 12c), besides $\mathrm{SO}_{4}{ }^{2-}, \mathrm{S}^{2-}$ and $\mathrm{S}_{\mathrm{n}}{ }^{2-}$ were also identified at $161.9 \mathrm{eV}$ and $163.9 \mathrm{eV}$ respectively, in agreement with the reported values of these species (Acres et al., 2010a; Li et al., 2015b; Wang et al., 2016; Klauber et al., 2001). The polysulfide peak is wider than the other three samples (see FWHM values in Table 3), likely due to the presence of multiple polysulfide species with variable chain length. Additionally, elemental sulphur $\left(\mathrm{S}^{0}\right)$ and sulfite $\left(\mathrm{SO}_{3}{ }^{2-}\right)$ were also detected at $164.4 \mathrm{eV}$ and 165.5 $\mathrm{eV}$ respectively. The spectrum could only be fit well when these two species were included, and the peak position of $\mathrm{SO}_{3}{ }^{2-}$ is in agreement with reported values for leached chalcopyrite ( $\mathrm{Li}$ et al., 2010; $\mathrm{Li}$ et al., 2014) or sodium sulfite (Swartz et al., 1971). Elemental sulphur, sulfite, and sulphate are normally absent on freshly fractured chalcopyrite (Li et al., 2014); hence, their presence indicate advanced surface oxidation of chalcopyrite in air. Overall, the XPS resutls of unleached chalcopyrite indicate the presence of an oxised thin film on the surface but the presence of chalcopyrite suggests that the surface was not entirely covered by the oxidised film. Also, the presence of multiple sulphur speices suggests that surface oxidation of chalcopyrite in air is a progressive process from the lowest valence state $\left(\mathrm{S}^{2-}\right)$ to the intermediate valence states $\left(\mathrm{S}_{2}{ }^{2-}, \mathrm{S}_{\mathrm{n}}{ }^{2-}, \mathrm{S}^{0}, \mathrm{SO}_{3}{ }^{2-}\right)$, and finally to the highest valence state $\left(\mathrm{SO}_{4}{ }^{2-}\right)$.

The sample leached under solvent-free condition for $148 \mathrm{~h}$ contained 11 at.\% $\mathrm{Cu}, 13$ at.\% Fe, 54 at.\% $\mathrm{S}$ and 23 at.\% $\mathrm{O}$ (Table 2). The presence of the weak $\mathrm{Cu}(\mathrm{I})-\mathrm{S}$ peak at $932.1 \mathrm{eV}$ in the $\mathrm{Cu} 2 \mathrm{p}$ spectrum (Fig. 12f), the weak Fe(III)-S peak at $708.2 \mathrm{eV}$ in the Fe 2p spectrum (Fig. 12g), and the weak peak of bulk $\mathrm{S}^{2-}$ at $161.1 \mathrm{eV}$ in the $\mathrm{S} 2 \mathrm{p}$ spectrum (Fig. 12h) suggest that a small portion of the grain surface is uncovered chalcopyrite. The presence of $\mathrm{Fe}(\mathrm{III})-\mathrm{OH} / \mathrm{SO}$ peak at $711 \mathrm{eV}$ in the Fe $2 \mathrm{p}$ spectrum (Fig. $12 \mathrm{~g}$ ), the presence of $\mathrm{SO}_{4}{ }^{2-}$ in the $\mathrm{S} 2 \mathrm{p}$ spectrum (Fig. $12 \mathrm{~h}$; Table 3), and the presence of $\mathrm{OH}^{-} / \mathrm{SO}_{4}{ }^{2-}$ and $\mathrm{H}_{2} \mathrm{O}$ in the $\mathrm{O}$ 1s spectrum (Fig. 12j) suggest the possible $\mathrm{Fe}(\mathrm{III})$ hydroxide and sulphate phases. However, due to the acidic leaching condition, $\mathrm{Fe}(\mathrm{III})$ hydroxide is unlikely. The absence of $\mathrm{K}$ in the $\mathrm{K}$ $2 p$ spectrum precludes the formation of potassium jarosite (Fig. 12i). Hence, the possible phase is hydrated iron sulphate, $\mathrm{Fe}_{2}\left(\mathrm{SO}_{4}\right)_{3} \cdot \mathrm{xH}_{2} \mathrm{O}$. Importantly, in the $\mathrm{S} 2 \mathrm{p}$ spectrum (Fig. 12h), besides polysulfide species $\mathrm{S}_{\mathrm{n}}{ }^{2}$, significant amount of elemental sulphur was detected, accounting for $23 \%$ of all sulphur species (Table 3). This contrasts the PXRD results (Fig. 5a), showing no elemental sulphur, most likely due to the small quantity and only present on the surface as a thin film. The abundant $S_{2}{ }^{2-}$ 
and $\mathrm{S}_{\mathrm{n}}{ }^{2-}$ may indicate the progressive oxidation from $\mathrm{S}^{2-}$ to $\mathrm{S}_{2}{ }^{2-}$ and then to $\mathrm{S}_{\mathrm{n}}{ }^{2-}$ and finally to elemental sulphur (Steudel, 1996).

The sample leached under solvent-free condition for a longer time of $500 \mathrm{~h}$ contained much less $\mathrm{Cu}(4$ at.\%), Fe (7 at.\%), and S (15 at.\%), but much more O (62 at.\%). Additionally, the sample also showed the presence of K (12 at.\%) (Table 2). The absence of Fe(III)-S (Fig. 12l) and $\mathrm{S}^{2-}$ (Fig. 12m) suggest that chalcopyrite was no longer present on the surface. Hence, the presence of $\mathrm{Cu}(\mathrm{I})-\mathrm{S}$ at $932.1 \mathrm{eV}$ (Fig. $12 \mathrm{k}$ ) and $\mathrm{S}_{\mathrm{n}}{ }^{2-}$ (Fig. 12m) may suggest the formation of copper polysulphides; however, this phase was not detected by PXRD (Fig. 5b), likely due to too small quantity. The presence of another peak at 934.6 $\mathrm{eV}$ in the $\mathrm{Cu} 2 \mathrm{p}$ spectrum (Fig. 12k) could be assigned to $\mathrm{Cu}$ (II)-OH or $\mathrm{Cu}$ (II)-SO. Considering the acidic leaching condition, the formation of copper hydroxide is unlikely; the presence of $\mathrm{SO}_{4}{ }^{2-}$ (Fig. $12 \mathrm{~m}$ ) and $\mathrm{H}_{2} \mathrm{O}$ (Fig. 12o) suggest the possible formation of trace $\mathrm{CuSO}_{4} \cdot 5 \mathrm{H}_{2} \mathrm{O}$ on surface due to recrystallization during drying of the residue leaching solution on the grain surface. The presence of $\mathrm{Fe}(\mathrm{III})-\mathrm{OH} / \mathrm{SO}$ (Fig. 12l), abundant $\mathrm{SO}_{4}{ }^{2-}$ (Fig. 12m; Table 3), $\mathrm{K}$ (Fig. 12n), and $\mathrm{OH}^{-} / \mathrm{SO}_{4}{ }^{2-}$ (Fig. 12o; Table 4) confirm the presence of potassium jarosite. This is in agreement with PXRD (Fig. 5b) and SEM-EDS (Fig. 6c and d). The relative smaller quantity of physisorbed $\mathrm{H}_{2} \mathrm{O}$ and electrically isolated $\mathrm{H}_{2} \mathrm{O}$ when compared with unleached chalcopyrite and solvent-free $148 \mathrm{~h}$ samples (Fig. 12d, i, n; Table 4) is also in agreement with the presence of jarosite because the surface of jarosite has been reported to be hydrophobic (Asokan et al., 2006), thus minimized water adsorption. In the S $2 p$ spectrum, only small quantity (3 at.\%) of elemental sulphur was detected (Table 3), much smaller than 15.8(3) wt.\% of elemental sulphur detected by PXRD (Fig. 5b). However, this is in agreement with SEM-EDS (Fig. 6d) and FIB-SEM tomography (Fig. 10a) that most elemental sulphur of this sample was between the outer jarosite shell and the unleached chalcopyrite core.

The sample leached under TCE20 condition for $218 \mathrm{~h}$ contained 3 at. $\% \mathrm{Cu}, 4$ at.\% Fe, 24 at.\% S, 10 at. $\% \mathrm{~K}$, and 59 at.\% $\mathrm{O}$, similar to elemental quantities of the solvent-free $500 \mathrm{~h}$ sample (Table 2). The presence of $\mathrm{Cu}(\mathrm{I})-\mathrm{S}$ at $932.1 \mathrm{eV}$ (Fig. 12p), surface $\mathrm{S}^{2-}$ at $160.9 \mathrm{eV}$ and $\mathrm{S}_{\mathrm{n}}{ }^{2-}$ at $163.4 \mathrm{eV}$ (Fig. 12r; Table 3) (Li et al., 2015a; Li et al., 2015b; Li et al., 2016), and the absence of Fe(III)-S (Fig. 12q) suggest the absence of chalcopyrite and the possible formation of $\mathrm{Cu}_{2} \mathrm{~S}$ or copper polysulfides; however, these 
phases were not detected by PXRD (Fig. 5d), likely due to too small quantity. For the same reasons as explained for the solvent-free $500 \mathrm{~h}$ sample, trace $\mathrm{CuSO}_{4} \cdot 5 \mathrm{H}_{2} \mathrm{O}$ could be formed on the surface and potassium jarosite is the dominant surface phase, based on the $\mathrm{Cu} 2 \mathrm{p}, \mathrm{S} 2 \mathrm{p}, \mathrm{K} 2 \mathrm{p}$, and $\mathrm{O} 1 \mathrm{~s}$ spectra (Figs. 12p, r, s, t). The main difference to the solvent-free $500 \mathrm{~h}$ sample is that in this TCE20 $218 \mathrm{~h}$ sample, much more $\mathrm{S}_{\mathrm{n}}{ }^{2-}$ and $\mathrm{S}^{0}$ were detected (cf. Fig. $12 \mathrm{~m}$ and r). This is in agreement with FIB-SEM tomography results that the embedded elemental sulphur in the jarosite shell exposed on the outer surface (Fig. 10), and was detected by XPS.

\section{Discussion}

\subsection{Removing sulphur passivation by tetrachloroethylene}

The fast leaching rate with the addition of TCE and the evidence from PXRD, SEM-EDS, and XPS strongly suggest the removal of sulphur passivation by TCE at the early stage of leaching. To confirm this mechanism, some of the separated TCE after the leaching experiments in TCE20 for 218 hours was left for complete evaporation, and the remnant solid was analysed using SEM-EDS and PXRD (Fig. 13). PXRD did not identify any other phases except elemental sulphur $\left(\mathrm{S}_{8}\right.$ with an orthorhombic structure), and EDS also identified elemental sulphur, with a minor amount of oxygen (likely from the TCE residue) and carbon (due to carbon coating). The solubility of sulphur in TCE has been measured to be $24.79 \mathrm{~g} \mathrm{~L}^{-1}$ at $25{ }^{\circ} \mathrm{C}$ (Seidell and Linke, 1941), and the present study determined that sulphur solubility in TCE at $75{ }^{\circ} \mathrm{C}$ is much higher, $70.25 \mathrm{~g} \mathrm{~L}^{-1}$. This solubility is in excess of the maximum sulphur initial content expected from the TCE20 and TCE10 experiments. The amount of chalcopyrite used in these experiments $(2.0 \mathrm{~g})$ corresponds to a maximum of $0.7 \mathrm{~g}$ of $\mathrm{S}$ and TCE10 and TCE20 experiments contained $50 \mathrm{~mL}$ and $100 \mathrm{~mL}$ of TCE, capable of dissolving $3.51 \mathrm{~g}$ and $7.03 \mathrm{~g}$ sulphur at $75^{\circ} \mathrm{C}$, respectively. Hence, it can be concluded that the removal of sulphur into the non-aqueous TCE phase plays a very significant role in the enhancement of the chalcopyrite dissolution rate in aqueous acid sulphate solutions.

Quantitative PXRD analyses found small traces of elemental sulphur (2.5 wt \%) in the TCE20 solid residues, but none was detected in the residues from TCE10. FIB-SEM-tomography clearly revealed that some elemental sulphur embedded in the jarosite phase could not be dissolved by TCE at the more 
advanced stage of leaching (in the case of TCE20) (Fig. 10b). XPS also detected sulphur on the surface of the TCE20 sample. This is because at the more advanced stage of leaching (in the case of TCE20), some sulphur was embedded in the jarosite phase and could not be dissolved by TCE. The jarosite abundance in the TCE20 sample is $82.0 \mathrm{wt} \%$ while in the TCE10 sample is $37.1 \mathrm{wt} \%$ (Fig. 5c \& d).

On the other hand, the determined sulphur solubility in DMSO at $75{ }^{\circ} \mathrm{C}$ is only $1.86 \mathrm{~g} \mathrm{~L}^{-1}$. Although this is higher than the reported sulphur solubility in DMSO at $25^{\circ} \mathrm{C}, 1.01 \mathrm{~g} \mathrm{~L}^{-1}$ (Zheng et al., 2015), the leaching results in the present study suggest that DMSO as a sulphur removal solvent does not have higher efficiency and is even slightly less efficient than solvent-free leaching (Fig. 4a). In this case, the DMSO10 experiment was performed with $50 \mathrm{~mL}$ of DMSO, capable of dissolving about $13.3 \%$ of total sulphur from chalcopyrite oxidation. Additionally, DMSO, also a polar solvent, may not act as a stabiliser for hydrogen peroxide as reported for other polar solvents such as acetone and ethylene glycol (Jorjani and Ghahreman, 2017; Mahajan et al., 2007; Solis-Marcíal and Lapidus, 2013).

This direct comparison of the two solvents suggest that TCE is a far better solvent than DMSO for the purpose of removing sulphur. Because TCE is non-toxic, immiscible with water, and has a high density of $1.62 \mathrm{~g} \mathrm{~cm}^{-3}$, it is easily separated from water. Once separated, sulphur can be recovered by cooling because sulphur solubility drops during cooling. TCE can then be recycled back into the reactor.

\subsection{Reaction stoichiometry}

During the leaching experiments, the volume of consumed $\mathrm{H}_{2} \mathrm{O}_{2}$ solution was recorded (Fig. 14a). To examine the possible reaction mechanisms operating in these experiments, data from Fig. $4 \mathrm{a}$ and $14 \mathrm{a}$ were recalculated to show the amount of copper released into the solution as a function of the amount of oxidant $\left(\mathrm{H}_{2} \mathrm{O}_{2}\right)$ added (Fig. 14b).

By assuming a complete breakdown of the chalcopyrite and exchange of the electrons only with hydrogen peroxide, Reactions 2 and 3 leave the sulphur product in its minimum and maximum oxidation states, respectively. Assuming the iron released is oxidized to the +3 state, stoichiometric ratios $(\mathrm{R})$ in the range of $0.12<\mathrm{CuFeS}_{2} / \mathrm{H}_{2} \mathrm{O}_{2}<0.40$ are expected. These ideal ratios are plotted in Fig. $14 \mathrm{~b}$ as $\mathrm{R}=$ 0.12 and $\mathrm{R}=0.40$. 


$$
\begin{aligned}
& \mathrm{CuFeS}_{2}+2 \frac{1}{2} 2 \mathrm{H}_{2} \mathrm{O}_{2}+5 \mathrm{H}^{+} \rightarrow \mathrm{Cu}^{2+}+\mathrm{Fe}^{3+}+2 \mathrm{~S}^{0}+5 \mathrm{H}_{2} \mathrm{O} \quad(\mathrm{R}=0.40) \\
& \mathrm{CuFeS}_{2}+8 \frac{1}{2} \mathrm{H}_{2} \mathrm{O}_{2}+\mathrm{H}^{+} \rightarrow \mathrm{Cu}^{2+}+\mathrm{Fe}^{3+}+2 \mathrm{SO}_{4}^{2-}+9 \mathrm{H}_{2} \mathrm{O} \quad(\mathrm{R}=0.12)
\end{aligned}
$$

Both the solvent-free and the DMSO10 experiments appear, in the initial stages, to adhere to the stoichiometry expressed in Reaction 3. Removing the sulphur produced in the reaction by the addition of TCE appears to produce the stoichiometry expressed by Reaction 2 .

The evolution of $\mathrm{pH}$ measured during chalcopyrite leaching (Fig. 15), indicates a significant increase from 1.1 to 1.4-1.6 in all the leaching solutions in the initial stage of the experiment. This was followed by a trend toward lower $\mathrm{pH}$ over the subsequent time for all experiments. These $\mathrm{pH}$ values represent the balance between the consumption and production of protons during the reactions in each experiment. Based on this observation, we propose a two-step mechanism. Firstly, the protons are consumed, and the sulphide is transformed into elemental sulphur during the initial stages of leaching (Reaction 2) (Li et al., 2016); and this is the reason for the rapid initial pH increase (Fig. 15). Secondly, elemental sulphur is converted into sulphate ions, which generates hydrogen ions (Reaction 4), explaining the drop of $\mathrm{pH}$ after the first step (Fig. 15).

$$
\mathrm{S}^{0}+3 \mathrm{H}_{2} \mathrm{O}_{2} \rightarrow \mathrm{SO}_{4}{ }^{2-}+2 \mathrm{H}_{2} \mathrm{O}+2 \mathrm{H}^{+}
$$

The overall result of Reactions 2 and 4 is Reaction 3. Similar pH curves were also measured in the study of (Ruiz-Sánchez and Lapidus, 2017). In our study, a sharper decrease in the pH for both solvent-free and DMSO10 solutions could be due to Reaction 4, because more sulphur remained on the surface of the particles and was oxidised. As a result, more hydrogen ions could have been generated in this solution than in the experiments with TCE10 and TCE20 solutions (Fig. 15). In the leaching with TCE, the produced elemental sulphur from Reaction 2 is dissolved in the TCE phase and is recovered without further oxidation to sulphate.

$$
\mathrm{S}^{0}+\mathrm{C}_{2} \mathrm{Cl}_{4} \rightarrow \mathrm{S}^{0} \cdot \mathrm{C}_{2} \mathrm{Cl}_{4}
$$

On the other hand, the $\mathrm{Fe}^{3+}$ produced from Reactions 2 and 3 also acts as an oxidant, contributing to chalcopyrite leaching, (Li et al., 2016) 


$$
\mathrm{CuFeS}_{2}+4 \mathrm{Fe}^{3+} \rightarrow \mathrm{Cu}^{2+}+5 \mathrm{Fe}^{2+}+\mathrm{S}^{0}
$$

and, the regeneration of $\mathrm{Fe}^{3+}$ from $\mathrm{Fe}^{2+}$ oxidation by $\mathrm{H}_{2} \mathrm{O}_{2}$ consumes $\mathrm{H}^{+}$, increasing the $\mathrm{pH}$ ( $\mathrm{Li}$ et al., 2015a; Li et al., 2015b).

$$
2 \mathrm{Fe}^{2+}+2 \mathrm{H}^{+}+2 \mathrm{H}_{2} \mathrm{O}_{2} \rightarrow 2 \mathrm{Fe}^{3+}+2 \mathrm{H}_{2} \mathrm{O}
$$

At the later stages, the solution becomes supersaturated with respect to jarosite, causing its precipitation.

$$
3 \mathrm{Fe}^{3+}+2 \mathrm{SO}_{4}{ }^{2-}+6 \mathrm{H}_{2} \mathrm{O}+\mathrm{K}^{+} \rightarrow 6 \mathrm{H}^{+}+\mathrm{KFe}_{3}\left(\mathrm{SO}_{4}\right)_{2}(\mathrm{OH})_{6}(\mathrm{~K} \text {-jarosite })
$$

\subsection{Jarosite formation at the later stage of leaching}

In addition to elemental sulphur, jarosite was a major product at the later stages of leaching. The inclusion of TCE as a separate liquid phase did not repress the formation of this product. There has been a lot of debate on jarosite formation and its limiting or passivating effect on chalcopyrite leaching. Jarosite minerals were reported in previous studies as passivating the reaction (Córdoba et al., 2009; Parker et al., 2003; Sandström et al., 2005) while some researchers suggested jarosite minerals formation was not the reaction limiting mechanism (Yang et al., 2015b). With no added iron or potassium salts in our experiments, jarosite could not start precipitating until the leaching solution was supersaturated with the components $\left(\mathrm{K}^{+}, \mathrm{SO}_{4}^{-2}\right.$ and $\mathrm{Fe}^{+3}$ in the case of potassium jarosite), so passivation from this reaction product would not be expected until the reaction had progressed to a certain stage. Jarosite was detected as small precipitated particles on the surface of the chalcopyrite particles during TCE10 and TCE20 at 116 and 90 hours, respectively (Fig. 7 \& 8). As shown in Fig. 4, this point marks a reduction in the copper extraction rate and the reduction in iron extraction in both experiments.

In the DMSO10 and solvent-free (148 h) experiments, no jarosite was detected (Fig. 5, 6a \& b, 9). This is most likely due to the low reaction extent of chalcopyrite leaching, such that not enough iron was iron released from leaching and hence the solutions were still undersaturated with respect to jarosite. This is evident from plotting Fe extraction against $\mathrm{Cu}$ extraction from the extraction data of Fig. 4 (Fig. 16). From the equimolar stoichiometry of $\mathrm{Cu}$ and $\mathrm{Fe}$ in chalcopyrite, the extracted copper to iron ratio would be expected to remain at a value of unity for the experiment duration. However, when significant amounts of jarosite formed, the Fe did not remain in solution, and the molar ratio of $\mathrm{Fe} / \mathrm{Cu}$ decreased 
as time progressed. As shown in Fig. 16, jarosite started to form when ca $40 \%$ of $\mathrm{Cu}$ was extracted for the TCE experiments, but in the case of DMSO10, only ca $22 \%$ was extracted, hence did not reach the point for jarosite precipitation. An interesting feature was observed for the solvent-free experiment that more $\mathrm{Fe}$ than $\mathrm{Cu}$ was extracted into the solution at the early stages up to ca $35 \%$ extraction, leaving behind a solid phase somewhat enriched in $\mathrm{Cu}$. As PXRD did not detect other copper iron sulphide phase other than chalcopyrite (Fig. 9a), the Cu-enriched phase may have the same structure of chalcopyrite. In the later stages of the solvent-free experiment after $40 \%$ extraction, the $\mathrm{Fe} / \mathrm{Cu}$ ratio decreased due to jarosite precipitation.

The formation of jarosite is most likely due to a coupled dissolution-precipitation mineral replacement mechanism (Altree-Williams et al., 2015; Putnis, 2009), a widely accepted mechanism responsible for a range of mineral-fluids reactions including ore minerals such as the replacement of pentlandite $\left(\mathrm{Fe}_{4.5} \mathrm{Ni}_{4.5} \mathrm{~S}_{9}\right)$ by violarite $\left(\mathrm{Ni}_{2} \mathrm{FeS}_{4}\right)(\mathrm{Xia}$ et al., 2009$)$, pyrrhotite $\left(\mathrm{Fe}_{7} \mathrm{~S}_{8}\right)$ by pyrite $\left(\mathrm{FeS}_{2}\right)(\mathrm{Qian}$ et al., 2011), and calaverite $\left(\mathrm{AuTe}_{2}\right)$ by gold (Au) (Zhao et al., 2013). This mechanism has been proposed for leaching of ilmenite, which effectively removes iron from ilmenite, forming rutile (Janssen and Putnis, 2011; Janssen et al., 2018). According to this mechanism, the dissolution of chalcopyrite is coupled with the precipitation of the jarosite through the interfacial fluid between the two phases. Once sufficient chalcopyrite is dissolved (40\% in this case) the interfacial fluid becomes supersaturated with respect to jarosite, and hence precipitation occurs at or near the dissolution sites. As the replacement proceeds, the interfacial fluid layer moves from the surface to the interior of the chalcopyrite grain (shrinking core), and a jarosite layer continues to grow on existing jarosite and increases its thickness. Hence, the jarosite forms a shell covering the remaining chalcopyrite core and approximately preserving the shape of the initial chalcopyrite grain.

The product phase from mineral replacement reactions is always porous (Putnis, 2015; Xia et al., 2014), due to the solubility difference between the primary mineral and the product mineral and more importantly due to the molar volume difference between the two phases. The molar volume of potassium jarosite is $156.75 \mathrm{~cm}^{3} \mathrm{~mol}^{-1}$ while that of chalcopyrite is $42.83 \mathrm{~cm}^{3} \mathrm{~mol}^{-1}$. Assuming all released iron from chalcopyrite precipitates as jarosite, the replacement of chalcopyrite by jarosite 
involves a volume increase of $+21.5 \%$. This effect explains the low porosity $(0.7 \%)$ in the jarosite phase in the solvent-free experiment (Fig. 10a).

The difference of porosity in the jarosite shell revealed by FIB-SEM tomography for solvent-free and TCE experiments explain the different leaching kinetics after the formation of jarosite in both cases. In the solvent-free experiment, the jarosite shell was slightly porous (Fig. 10a); the formation of jarosite followed the oxidation of elemental sulphur to sulphate (Fig. 14); hence, sulphur passivation was effectively reduced, and leaching rate after the formation of a permeable jarosite was enhanced (Fig. 4a). In contrast, in the case of leaching with TCE, some sulphur was trapped in the jarosite shell before it was dissolved in TCE. The trapped sulphur effectively filled the porosity and resulted in a nearly impermeable jarosite shell (Fig. 10b); hence, the leaching rate was significantly reduced after the formation of the passivating jarosite shell.

\subsection{Thermodynamic and kinetic aspects of jarosite formation}

It is clear that to enhance chalcopyrite leaching, removing both sulphur passivation at the early stage and jarosite passivation at the later stage is necessary. While adding TCE effectively removes sulphur passivation at the early stage, the overall cupper extraction was limited by the jarosite passivation at the later stage. The formation of jarosite is driven by both thermodynamics and kinetics. From the Eh-pH diagram (Fig. 17a), without suppressing hematite and goethite, the leaching condition of this study sits within the stability field of hematite. Reaction modelling predicts that the solution is quickly saturated with respect to hematite after $<5 \%$ of chalcopyrite is dissolved (Fig. 17b), and subsequently hematite precipitation occurs until all chalcopyrite has reacted (Fig. 17c). However, hematite was not observed in the experiments, and only jarosite- $\mathrm{K}$ was observed. This means that jarosite- $\mathrm{K}$ is a metastable phase relative to hematite and goethite. Only after both hematite and goethite are suppressed in thermodynamic modelling, the Eh-pH diagram shows jarosite-K (Fig. 17d), and in this case the leaching condition of this study sits within the stability field of jarosite-K. Because hematite and goethite are not allowed to precipitate after the solution reaches saturation with respect to these two minerals, the saturation indexes of hematite and goethite reach very high levels (Fig. 17e), and only then the solution 
reaches saturation with respect to jarosite- $\mathrm{K}$ and jarosite-K starts precipitating after $15 \%$ of chalcopyrite is dissolved (Fig. 17f).

The other observation of the Eh-pH diagrams is that sulphur is not the stable form under the leaching condition, and it should be oxidised to sulphate. This suggests that the formation of sulphur is also controlled by kinetics, meaning that further oxidation is not quick enough to remove surface passivation. Adding TCE dissolves sulphur and stops its further oxidation.

The thermodynamic and reaction modelling suggests that the leaching solution does not reach saturation with respect to the other forms of jarosite (e.g., jarosite-Na, hydronium jarosite), and only jarosite-K can precipitate from the solution, and that the formation of jarosite- $\mathrm{K}$ is kinetically favoured compared with the thermodynamically more stable phases hematite and goethite. To reduce the formation of jarosite-K, careful control of the composition of the leaching solution is important. This can be done by removing K-bearing minerals (e.g., K-feldspar) before leaching by froth flotation and keeping ferric iron concentration at low levels.

\subsection{The proposed mechanisms}

Based on the experimental evidences, it is clearly that distinctly different mechanisms are responsible for chalcopyrite leaching with and without TCE. The proposed mechanisms for the leaching conditions in this work are illustrated in Fig. 18. Without TCE, the oxidation of chalcopyrite first forms a surface layer of elemental sulphur causing passivation. This layer is slowly removed by oxidation to sulphate and partially removed at the middle stage of leaching. Hence, the leaching rate is enhanced. At the later stage, when the solution reaches saturation with respect to jarosite-K, a jarosite-K shell is formed but this shell seems to be permeable and does not slow down leaching, even with further growing to a thicker layer. In contrast, if TCE is added into the leaching solution, elemental sulphur produced from chalcopyrite oxidation is quickly dissolved into the TCE phase, exposing the fresh surface of chalcopyrite to the leaching solution. This prevents sulphur passivation and promotes rapid leaching at the early stage. However, after the formation of a jarosite-K shell at the later stage, passivation occurs, due to the fact that some sulphur fill the pores in the jarosite shell, making it nearly impermeable. Jarosite-K continue to grow, with insignificant further leaching of chalcopyrite. 


\section{Conclusions}

We studied the effects of tetrachloroethylene (TCE) and dimethyl sulfoxide (DMSO) on chalcopyrite leaching in aqueous acid sulphate solutions at $75{ }^{\circ} \mathrm{C}$ and $750 \mathrm{mV}$ (SHE), and observed that TCE, a nonpolar solvent, is very effective in removing passivating elemental sulphur from chalcopyrite surface, enhancing the leaching rate by six times compared to leaching in a TCE-free solution. In contrast, DMSO, a polar solvent, has low sulphur solubility and was not effective in reducing sulphur passivation. At the later stage of leaching, the concentration of ferric ions increased, resulting in the formation of a potassium jarosite shell covering an undissolved chalcopyrite core. The jarosite-K is porous with no passivation effect in TCE-free leaching; but after adding TCE, the porosity is filled with elemental sulphur, and the nonporous shell passivates at the later stage of leaching. These results provide insights into the chalcopyrite leaching process and the relative importance of inhibition by the reaction products, sulphur at the early stage and jarosite-K at the later stage. Adding TCE prevents sulphur passivation, but careful control of solution composition is necessary to eliminate the formation of jarosite- $\mathrm{K}$ at the later stages of leaching. This study sheds light on developing commercially more viable sulphur removing solvents which should have higher sulphur solubility, lower health and safety risks, more environmental friendliness, higher recyclability, and lower cost.

\section{Acknowledgements}

The authors would like to thank Elaine Miller, Veronica Avery and Jean-Pierre Veder at the John de Laeter Centre at Curtin University for their assistance with SEM-EDS, PXRD and XPS analyses, and Juita Juita at Murdoch University for her assistance with ICP-MS analysis. The authors also thank Prof. Allan Pring for providing the chalcopyrite sample and Dr. Gujie Qian for advice on setting up the leaching reactor, the Australian Synchrotron for the powder diffraction beam time, and Pawsey Supercomputing Centre for using Avizo software. We thank two anonymous reviewers for their constructive comments. M. Kartal acknowledges Murdoch University for a Murdoch International Postgraduate Scholarship (MIPS) and AINSE Limited for providing a PGRA award. F. Xia acknowledges the Australian Research Council for a Discovery Project (DP170101893). 


\section{References}

Abed, N., 2002. The sonochemical leaching of Chalcopyrite, University of British Columbia. PhD thesis.

Acres, R.G., Harmer, S.L. and Beattie, D.A., 2010a. Synchrotron XPS studies of solution exposed chalcopyrite, bornite, and heterogeneous chalcopyrite with bornite. Int J Miner Process, 94(1-2): 43-51.

Acres, R.G., Harmer, S.L. and Beattie, D.A., 2010b. Synchrotron XPS, NEXAFS, and ToF-SIMS studies of solution exposed chalcopyrite and heterogeneous chalcopyrite with pyrite. Miner Eng, 23(1113): 928-936.

Ahn, J., Wu, J. and Lee, J., 2019. Investigation on chalcopyrite leaching with methanesulfonic acid (MSA) and hydrogen peroxide. Hydrometallurgy, 187: 54-62.

Altree-Williams, A., Pring, A., Ngothai, Y. and Brugger, J., 2015. Textural and compositional complexities resulting from coupled dissolution-reprecipitation reactions in geomaterials. Earth Sci Rev, 150: 628-651.

Asokan, P., Saxena, M. and Asolekar, S.R., 2006. Hazardous jarosite use in developing non-hazardous product for engineering application. J Hazard Mater, 137(3): 1589-1599.

Aydogan, S., Aras, A. and Canbazoglu, M., 2005. Dissolution kinetics of sphalerite in acidic ferric chloride leaching. Chem Eng J, 114(1-3): 67-72.

Baláž, P., 2008. Mechanochemistry and nanoscience, Mechanochemistry in Nanoscience and Minerals Engineering. Springer, pp. 321-341.

Brion, D., 1980. Etude par spectroscopie de photoelectrons de la degradation superficielle de $\mathrm{FeS}_{2}$, $\mathrm{CuFeS}_{2}, \mathrm{ZnS}$ et PbS a l'air et dans l'eau. Appl Surf Sci, 5(2): 133-152.

Buckley, A.N. and Woods, R., 1984. An X-ray photoelectron spectroscopic study of the oxidation of chalcopyrite. Aust J Chem, 37(12): 2403-2413.

Córdoba, E., Muñoz, J., Blázquez, M., González, F. and Ballester, A., 2008a. Leaching of chalcopyrite with ferric ion. Part I: General aspects. Hydrometallurgy, 93(3-4): 81-87. 
Córdoba, E., Muñoz, J., Blázquez, M., González, F. and Ballester, A., 2008b. Leaching of chalcopyrite with ferric ion. Part II: Effect of redox potential. Hydrometallurgy, 93(3-4): 88-96.

Córdoba, E.M., Muñoz, J.A., Blázquez, M.L., González, F. and Ballester, A., 2009. Passivation of chalcopyrite during its chemical leaching with ferric ion at $68^{\circ} \mathrm{C}$. Miner Eng, 22(3): 229-235.

Crundwell, F., 1988. The influence of the electronic structure of solids on the anodic dissolution and leaching of semiconducting sulphide minerals. Hydrometallurgy, 21(2): 155-190.

Debernardi, G. and Carlesi, C., 2013. Chemical-Electrochemical Approaches to the Study Passivation of Chalcopyrite. Min Proc Ext Met Rev, 34(1): 10-41.

Dixon, D.G., Mayne, D.D. and Baxter, K.G., 2008. Galvanox ${ }^{\mathrm{TM}}$ - A Novel Galvanically-Assisted Atmospheric Leaching Technology for Copper Concentrates. Can Metall Quart, 47(3): 327-336.

Fairley, N., Carrick, A. and Fairly, N., 2005. The casa cookbook, 1. Acolyte Science, Cheshire.

Fairthorne, G., Fornasiero, D. and Ralston, J., 1997. Effect of oxidation on the collectorless flotation of chalcopyrite. Int J Miner Process, 49(1-2): 31-48.

Greczynski, G. and Hultman, L., 2017. C 1s peak of adventitious carbon aligns to the vacuum level: dire consequences for material's bonding assignment by photoelectron apectroscopy. ChemPhysChem, 18(12): 1507-1512.

Hackl, R., Dreisinger, D., Peters, 1., King, J., 1995. Passivation of chalcopyrite during oxidative leaching in sulfate media. Hydrometallurgy, 39(1-3): 25-48.

Harmer, S.L., Thomas, J.E., Fornasiero, D. and Gerson, A.R., 2006. The evolution of surface layers formed during chalcopyrite leaching. Geochim Cosmochim Ac, 70(17): 4392-4402.

Havlik, T. and Kammel, R., 1995. Leaching of chalcopyrite with acidified ferric chloride and carbon tetrachloride addition. Miner Eng, 8(10): 1125-1134.

Hidalgo, T., Kuhar, L., Beinlich, A. and Putnis, A., 2018. Kinetic study of chalcopyrite dissolution with iron(III) chloride in methanesulfonic acid. Miner Eng, 125: 66-74. 
Hill, R. and Howard, C., 1987. Quantitative phase analysis from neutron powder diffraction data using the Rietveld method. J Appl Crystallogr, 20(6): 467-474.

Janssen, A. and Putnis, A., 2011. Processes of oxidation and HCl-leaching of Tellnes ilmenite. Hydrometallurgy, 109(3-4): 194-201.

Janssen, A., Putnis, A., Geisler, T. and Putnis, C.V., 2018. The experimental replacement of ilmenite by rutile in $\mathrm{HCl}$ solutions. Mineral Mag, 74(4): 633-644.

Jorjani, E. and Ghahreman, A., 2017. Challenges with elemental sulfur removal during the leaching of copper and zinc sulfides, and from the residues; a review. Hydrometallurgy, 171: 333-343.

Khmeleva, T., Georgiev, T., Jasieniak, M., Skinner, W. and Beattie, D., 2005. XPS and ToF-SIMS study of a chalcopyrite-pyrite-sphalerite mixture treated with xanthate and sodium bisulphite. Surf Interface Anal, 37(8): 699-709.

Klauber, C., 2008. A critical review of the surface chemistry of acidic ferric sulphate dissolution of chalcopyrite with regards to hindered dissolution. Int J Miner Process, 86(1-4): 1-17.

Klauber, C., Parker, A., van Bronswijk, W. and Watling, H., 2001. Sulphur speciation of leached chalcopyrite surfaces as determined by X-ray photoelectron spectroscopy. Int J Miner Process, 62(1-4): 65-94.

Klein, J.C., Proctor, A., Hercules, D.M. and Black, J.F., 1983. X-ray excited Auger intensity ratios for differentiating copper compounds. Anal Chem, 55(13): 2055-2059.

Knight, K.S., Marshall, W.G. and Zochowski, S.W., 2011. The low-temperature and high-pressure thermoelastic and structural properties of chalcopyrite, CuFeS2. Can Mineral, 49(4): 1015-1034.

Knipe, S.W., Mycroft, J.R., Pratt, A.R., Nesbitt, H.W. and Bancroff, G.M., 1995. X-ray photoelectron spectroscopic study of water adsorption on iron sulphide minerals. Geochim. Cosmochim. Acta, 59(6): 1079-1090.

Li, J., Kawashima, N., Kaplun, K., Absolon, V.J. and Gerson, A.R., 2010. Chalcopyrite leaching: The rate controlling factors. Geochim Cosmochim Ac, 74(10): 2881-2893. 
Li, Y., Chandra, A.P. and Gerson, A.R., 2014. Scanning photoelectron microscopy studies of freshly fractured chalcopyrite exposed to $\mathrm{O}_{2}$ and $\mathrm{H}_{2} \mathrm{O}$. Geochim Cosmochim Ac, 133: 372-386.

Li, Y., Qian, G., Li, J. and Gerson, A.R., 2015a. Chalcopyrite Dissolution at $650 \mathrm{mV}$ and $750 \mathrm{mV}$ in the Presence of Pyrite. Metals, 5(3): 1566-1579.

Li, Y., Qian, G., Li, J. and Gerson, A.R., 2015b. Kinetics and roles of solution and surface species of chalcopyrite dissolution at 650mV. Geochim Cosmochim Ac, 161: 188-202.

Li, Y., Wei, Z., Qian, G., Li, J. and Gerson, A., 2016. Kinetics and mechanisms of chalcopyrite dissolution at controlled redox potential of $750 \mathrm{mV}$ in sulfuric acid solution. Minerals, 6(3) 83 .

Mahajan, V., Misra, M., Zhong, K. and Fuerstenau, M., 2007. Enhanced leaching of copper from chalcopyrite in hydrogen peroxide-glycol system. Miner Eng, 20(7): 670-674.

McCusker, L., Von Dreele, R., Cox, D., Louër, D. and Scardi, P., 1999. Rietveld refinement guidelines. J Appl Crystallogr, 32(1): 36-50.

McIntyre, N.S. and Zetaruk, D.G., 1977. X-ray photoelectron spectroscopic studies of iron oxides. Anal Chem, 49(11): 1521-1529.

Menchetti, S., 1976. Crystal chemistry of the alunite series: crystal structure refinement of alunite and synthetic jarosite. Neu Jb Mineral, 406-417.

Mudd, G.M., 2010. The Environmental sustainability of mining in Australia: key mega-trends and looming constraints. Resour Policy, 35(2): 98-115.

Nava, D., González, I., Leinen, D. and Ramos-Barrado, J.R., 2008. Surface characterization by X-ray photoelectron spectroscopy and cyclic voltammetry of products formed during the potentiostatic reduction of chalcopyrite. Electrochim Acta, 53(14): 4889-4899.

Nazari, G., Dixon, D.G. and Dreisinger, D.B., 2012a. The mechanism of chalcopyrite leaching in the presence of silver-enhanced pyrite in the Galvanox ${ }^{\mathrm{TM}}$ process. Hydrometallurgy, 113-114: 122-130. 
Nazari, G., Dixon, D.G. and Dreisinger, D.B., 2012b. The role of silver-enhanced pyrite in enhancing the electrical conductivity of sulfur product layer during chalcopyrite leaching in the Galvanox ${ }^{\mathrm{TM}}$ process. Hydrometallurgy, 113-114: 177-184.

Nesbitt, H.W. and Muir, I.J., 1998. Oxidation states and speciation of secondary products on pyrite and arsenopyrite reacted with mine waste waters and air. Miner Petrol, 62(1-2): 123-144.

Nikkhou, F., Xia, F. and Deditius, A.P., 2019. Variable surface passivation during direct leaching of sphalerite by ferric sulfate, ferric chloride, and ferric nitrate in a citrate medium. Hydrometallurgy, 188: 201-215.

Parker, A., Klauber, C., Kougianos, A., Watling, H. and Van Bronswijk, W., 2003. An X-ray photoelectron spectroscopy study of the mechanism of oxidative dissolution of chalcopyrite. Hydrometallurgy, 71(1-2): 265-276.

Parmigiani, F., Pacchioni, G., Illas, F. and Bagus, P., 1992. Studies of the $\mathrm{Cu}-\mathrm{O}$ bond in cupric oxide by X-ray photoelectron spectroscopy and ab initio electronic structure models. J Electron Spectrosc relat phenom, 59(3): 255-269.

Pawley, G. and Rinaldi, R., 1972. Constrained refinement of orthorhombic sulphur. Acta Crystallogr B, 28(12): 3605-3609.

Peng, P., Chen, C., Li, S., Jiang, W., Liu, G., Wang, X., 2011. Coupling process of sphalerite concentrate leaching in $\mathrm{FeCl}_{3}-\mathrm{HCl}$ and tetrachloroethylene extracting of sulfur, Electronic and Mechanical Engineering and Information Technology (EMEIT), 2011 International Conference on. IEEE, pp. 1780-1783.

Peng, P., Xie, H. and Lu, L., 2005. Leaching of a sphalerite concentrate with $\mathrm{H}_{2} \mathrm{SO}_{4}-\mathrm{HNO}_{3}$ solutions in the presence of $\mathrm{C}_{2} \mathrm{Cl}_{4}$. Hydrometallurgy, 80(4): 265-271.

Putnis, A., 2009. Mineral replacement reactions. Rev Mineral Geochem, 70(1): 87-124.

Putnis, A., 2015. Transient porosity resulting from fluid-mineral interaction and its consequences. Rev Mineral Geochem, 80(1): 1-23. 
Qian, G., Xia, F., Brugger, J., Skinner, W.M., Bei, J., Chen, G., Pring, A., 2011. Replacement of pyrrhotite by pyrite and marcasite under hydrothermal conditions up to $220^{\circ} \mathrm{C}$ : An experimental study of reaction textures and mechanisms. Am Miner, 96(11-12): 1878-1893.

Reilly, I.G. and Scott, D.S., 1977. The leaching of a chalcopyrite concentrate in ammonia. Can J Chem Eng, 55(5): 527-533.

Ren, Y., Shui, H., Peng, C., Liu, H. and Hu, Y., 2011. Solubility of elemental sulfur in pure organic solvents and organic solvent-ionic liquid mixtures from 293.15 to 353.15K. Fluid Phase Equilib, 312: $31-36$.

Rietveld, H.M., 1969. A profile refinement method for nuclear and magnetic structures. J Appl Crystallogr, 2(2): 65-71.

Ruiz-Sánchez, Á. and Lapidus, G.T., 2017. Study of chalcopyrite leaching from a copper concentrate with hydrogen peroxide in aqueous ethylene glycol media. Hydrometallurgy, 169: 192-200.

Sandström, Å., Shchukarev, A. and Paul, J., 2005. XPS characterisation of chalcopyrite chemically and bio-leached at high and low redox potential. Miner Eng, 18(5): 505-515.

Seidell, A. and Linke, W.F., 1941. Solubilities of inorganic and metal organic compounds: a compilation of quantitative solubility data from the periodical literature, D. Van Nostrand, New York. Shirley, D.A., 1972. High-resolution X-ray photoemission spectrum of the valence bands of gold. Phys Rev B, 5(12): 4709-4714.

Solis-Marcíal, O.J. and Lapidus, G.T., 2013. Improvement of chalcopyrite dissolution in acid media using polar organic solvents. Hydrometallurgy, 131-132: 120-126.

Steudel, R., 1996. Mechanism for the formation of elemental sulfur from aqueous sulfide in chemical and microbiological desulfurization processes. Ind Eng Chem Res, 35(4): 1417-1423.

Stott, M., Watling, H., Franzmann, P. and Sutton, D., 2000. The role of iron-hydroxy precipitates in the passivation of chalcopyrite during bioleaching. Miner Eng, 13(10-11): 1117-1127. 
Suyantara, G.P.W, Hirajima, T., Miki, H., Sasaki, K., Yamane, M., Takida, E., Kuraiwa, S., Imaizumu, Y., 2018. Selective flotation of chalcopyrite and molybdenite using $\mathrm{H}_{2} \mathrm{O}_{2}$ oxidation method with the addition of ferrous sulfate. Miner Eng, 122: 312-326.

Swartz W. E., Wynne K. J. and Hercules D. M., 1971. X-ray photoelectron spectroscopy of group VIA elements. Anal. Chem. 43, 1884-1887.

Wang, J., Gan, X., Zhao, H., Hu, M., Li, K., Qin, W., Qiu, G., 2016. Dissolution and passivation mechanisms of chalcopyrite during bioleaching: DFT calculation, XPS and electrochemistry analysis. Miner Eng, 98: 264-278.

Watling, H.R., 2006. The bioleaching of sulphide minerals with emphasis on copper sulphides - A review. Hydrometallurgy, 84(1-2): 81-108.

Watling, H.R., 2013. Chalcopyrite hydrometallurgy at atmospheric pressure: 1. Review of acidic sulfate, sulfate-chloride and sulfate-nitrate process options. Hydrometallurgy, 140: 163-180.

Weian, D., 1997. Leaching behaviour of complex sulphide concentrates with ferric chloride by microwave irradiation. Rare Met, 16: 153.

Wu, N., Tian, W., Shen, J., Qiao, X., Sun, T., Wu, H., Zhao, J., Liu, X., Zhang, Y., 2019. Facile fabrication of a jarosite ultrathin $\mathrm{KFe}_{3}\left(\mathrm{SO}_{4}\right)_{2}(\mathrm{OH})_{6} @ \mathrm{rGO}$ nanosheet hybrid composite with pseudocapacitive contribution as a robust anode for lithium-ion batteries. Inorg Chem Front, 6(1): 192198.

Xia, F., Brugger, J., Chen, G., Ngothai, Y., O’Neill, B., Putnis, A., Pring, A., 2009. Mechanism and kinetics of pseudomorphic mineral replacement reactions: A case study of the replacement of pentlandite by violarite. Geochim Cosmochim Ac, 73(7): 1945-1969.

Xia, F. Zhao, J., Etschmann, B. E., Brugger, J., Garvey, C. J., Rehm, C., Lemmel, H., Ilavsky, J., Han, Y. S., Pring, A., 2014. Characterization of porosity in sulfide ore minerals: A USANS/SANS study. Am Miner, 99(11-12): 2398-2404. 
Yang, Y., Harmer, S. and Chen, M., 2015a. Synchrotron-based XPS and NEXAFS study of surface chemical species during electrochemical oxidation of chalcopyrite. Hydrometallurgy, 156: 89-98.

Yang, Y., Liu, W. and Chen, M., 2015b. XANES and XRD study of the effect of ferrous and ferric ions on chalcopyrite bioleaching at $30 \mathrm{C}$ and $48 \mathrm{C}$. Miner Eng, 70: 99-108.

Zhao, J., Brugger, J., Xia, F., Ngothai, Y., Chen, G., Pring, A., 2013. Dissolution-reprecipitation vs. solid-state diffusion: Mechanism of mineral transformations in sylvanite, $(\mathrm{AuAg})_{2} \mathrm{Te}_{4}$, under hydrothermal conditions. Am Miner, 98(1): 19-32.

Zheng, D., Zhang, X., Li, C., McKinnon, M.E., Sadok, R.G., Qu, D., Yu, X., Lee, H.S., Yang, X.Q., Qu, D., 2015. Quantitative chromatographic determination of dissolved elemental sulfur in the nonaqueous electrolyte for lithium-sulfur batteries. J Electrochem Soc, 162(1): A203-A206. 


\section{Figure captions}

Fig. 1. The unleached chalcopyrite. (a) PXRD pattern with Rietveld analysis; the red and black patterns are the data and calculated pattern respectively, while the green line shows the difference between the data and the calculated pattern; the vertical lines shows the Bragg positions of chalcopyrite (brown) and pyrite (blue); Rwp and $\chi^{2}$ are criteria of the fitting quality. The weight percentage of the phases are obtained from the fitting. (b) SE image of a typical grain, and (c) BSE image of the cross-section of a typical grain. (For interpretation of the references to colour in this figure, the reader is referred to the web version of this article.)

Fig. 2. Schematic illustration of the leaching reactor. (For interpretation of the references to colour in this figure, the reader is referred to the web version of this article.)

Fig. 3. The procedure of FIB-FESEM tomography slice and view analysis: (a) a representative particle is embedded into an epoxy resin block and polished, (b) a $200 \mathrm{~nm}$ Pt layer was ion beam deposited over the region of interest, (c) removal of the surrounding material, and (d) serial slice by FIB and image by SEM for approximately 200 slices.

Fig. 4. (a) $\mathrm{Cu}$ and (b) Fe extraction (\%) as a function of leaching time for the four leaching experiments.

Fig. 5. PXRD patterns and quantitative phase analyses of leached residues. (a) solvent-free at $148 \mathrm{~h}$, (b) solvent-free at $500 \mathrm{~h}$, (c) TCE10 at $304 \mathrm{~h}$, (d) TCE20 at $218 \mathrm{~h}$, and (e) DMSO10 at $237 \mathrm{~h}$. Rietveld refinement metrics and results are in the inset of each pattern. See Fig. 1 caption for more explanations. (For interpretation of the references to colour in this figure, the reader is referred to the web version of this article.)

Fig. 6. BSE images of the leached chalcopyrite residues in the solvent-free experiments. (a) grain surface after $148 \mathrm{~h}$, (b) grain cross-section after $148 \mathrm{~h}$, (c) grain surface after $500 \mathrm{~h}$, and (d) grain crosssection after $500 \mathrm{~h}$.

Fig. 7. BSE images of the leached chalcopyrite residues in the TCE10 experiments. (a) grain surface after $116 \mathrm{~h}$, (b) grain cross-section after $116 \mathrm{~h}$, (c) grain surface after $304 \mathrm{~h}$, and (d) grain cross-section after $304 \mathrm{~h}$. 
Fig. 8. BSE images of the leached chalcopyrite residues in the TCE20 experiments. (a) grain surface after 90 h, (b) grain cross-section after 90 h, (c) grain surface after 218 h, and (d) grain cross-section after $218 \mathrm{~h}$.

Fig. 9. BSE images of the leached chalcopyrite residues after $90 \mathrm{~h}$ in the DMSO10 experiment, showing (a) grain surface and (b) grain cross-section.

Fig. 10. FIB-SEM tomography data of jarosite shells from (a) solvent-free experiment at $500 \mathrm{~h}$, showing porosity, and (b) TCE20 experiment at $218 \mathrm{~h}$, showing holes and embedded sulphur. The green-yellowred and grey coloured isosurfaces represent the outer and inner surfaces of the jarosite shell. The grey colour is semi-transparent to reveal the pores (a) and embedded sulphur (b) in jarosite. Also see videos of these 3D reconstructions in the supporting information. (For interpretation of the references to colour in this figure, the reader is referred to the web version of this article.)

Fig. 11. Pore volume probability distribution function (PDF) measured using 3D tomographic analysis shown in Fig. 10a obtained from the jarosite layer of the sample leached in solvent-free experiment at $500 \mathrm{~h}$.

Fig. 12. XPS spectra showing $\mathrm{Cu} 2 \mathrm{p}, \mathrm{Fe} 2 \mathrm{p}, \mathrm{S} 2 \mathrm{p}, \mathrm{K} 2 \mathrm{p}$ and $\mathrm{O} 1 \mathrm{~s}$ peaks from the surface of samples collected from: (a-e) unleached chalcopyrite, (f-j) solvent-free experiment at $148 \mathrm{~h},(\mathrm{k}-\mathrm{o})$ solvent-free experiment at $500 \mathrm{~h}$, and (p-t) TCE20 experiment at $218 \mathrm{~h}$.

Fig. 13. (a) SEM image, (b) elemental EDS-map, (c) EDS spectra, and (d) PXRD pattern of extracted sulphur by TCE from TCE20 experiment at $218 \mathrm{~h}$. Rietveld refinement metrics and results are in the inset of each pattern. See Fig. 1 caption for more explanations. (For interpretation of the references to colour in this figure, the reader is referred to the web version of this article.)

Fig. 14. (a) The consumption of hydrogen peroxide with reaction time, and (b) copper extraction (mmol) as a function of hydrogen peroxide consumption (mmol). The linear lines with slopes $\mathrm{R}=0.40$ and $\mathrm{R}=0.12$ correspond to the overall reactions assuming sulphate and elemental sulphur are the final oxidised forms of $\mathrm{S}$ (see Reactions 1 and 2 and more descriptions in the text).

Fig. 15. The change of $\mathrm{pH}$ as a function of leaching time for the four leaching experiments. 
Fig. 16. Comparison of the extractions of $\mathrm{Fe}$ and $\mathrm{Cu}$. The linear dash line means equimolar extraction of $\mathrm{Fe}$ and $\mathrm{Cu}$.

Fig. 17. Thermodynamic analyses of the chalcopyrite leaching experiment at $75{ }^{\circ} \mathrm{C}$, comparing the conditions when hematite and goethite are not suppressed (a-c) and suppressed (d-f) in the modelling. (a, d) Eh-pH predominance diagram of the Fe-Cu-S-O system at $75{ }^{\circ} \mathrm{C}$. Dashed lines show the subdiagrams of sulphur (blue) and copper (green). The concentrations of ions are equivalent to $40 \%$ leaching of chalcopyrite in the solvent-free experiment: $\sum \mathrm{Fe}=0.00872 \mathrm{M}, \sum \mathrm{Cu}=0.00872 \mathrm{M}$, $\sum \mathrm{S}=0.06744 \mathrm{M},\left[\mathrm{K}^{+}\right]=0.001304 \mathrm{M}$, and $\left[\mathrm{Na}^{+}\right]=0.002492 \mathrm{M}$. The position of the red diamond means the leaching condition of this study. (b, e) Numerical modelling of chalcopyrite leaching, showing the saturation indexes of minerals. The starting solution composition is the same as the solvent-free experiment. This solution is progressively reacted with $2 \mathrm{~g}$ of chalcopyrite containing $1.63 \mathrm{mmol} \mathrm{K} \mathrm{K}^{+}$ and $3.11 \mathrm{mmol} \mathrm{Na}{ }^{+}$at fixed $\mathrm{Eh}$ at $750 \mathrm{mV}$. (c, f) Mineral precipitation as a function of reacted chalcopyrite. (For interpretation of the references to colour in this figure, the reader is referred to the web version of this article.)

Fig. 18. The proposed mechanisms of chalcopyrite leaching with and without tetrachloroethylene. Condition: $75{ }^{\circ} \mathrm{C}, 750 \mathrm{mV}, 0.05 \mathrm{M}$ sulphuric acid solution, and slurry density of $4 \mathrm{~g} \mathrm{~L}^{-1}$. (For interpretation of the references to colour in this figure, the reader is referred to the web version of this article.) 
Table 1. Major and minor metallic elements (wt.\%) in the chalcopyrite sample determined by ICP-MS.

\begin{tabular}{cccccccccc}
\hline $\mathrm{Cu}$ & $\mathrm{Fe}$ & $\mathrm{Na}$ & $\mathrm{K}$ & $\mathrm{Mg}$ & $\mathrm{Zn}$ & $\mathrm{Mn}$ & $\mathrm{Ca}$ & $\mathrm{Ni}$ & $\mathrm{Co}$ \\
\hline 28.26 & 24.45 & 3.58 & 3.18 & 0.75 & 0.66 & 0.51 & 0.21 & 0.08 & 0.02 \\
\hline
\end{tabular}

Table 2. Elemental quantifications (at.\%) of the unleached chalcopyrite, solvent-free at $148 \mathrm{~h}$ and $500 \mathrm{~h}$, and TCE20 at $218 \mathrm{~h}$ samples, derived from the survey XPS spectra.

\begin{tabular}{cccccc}
\hline $\begin{array}{c}\text { Element } \\
\text { core-level }\end{array}$ & $\begin{array}{c}\text { Average } \\
\text { binding } \\
\text { energy (eV) }\end{array}$ & $\begin{array}{c}\text { Starting } \\
\text { chalcopyrite }\end{array}$ & $\begin{array}{c}\text { Solvent-free } \\
148 \mathrm{~h}\end{array}$ & $\begin{array}{c}\text { Solvent-free } \\
500 \mathrm{~h}\end{array}$ & $\begin{array}{c}\text { TCE20 } \\
218 \mathrm{~h}\end{array}$ \\
\hline $\mathrm{Cu} 2 p$ & 932.4 & 17 & 11 & 4 & 3 \\
\hline $\mathrm{Fe} 2 p$ & 712.1 & 14 & 13 & 7 & 4 \\
\hline $\mathrm{S} 2 p$ & 164.5 & 56 & 53 & 15 & 24 \\
\hline $\mathrm{K} 2 p$ & 291.9 & 0 & 0 & 12 & 10 \\
\hline $\mathrm{O} 1 s$ & 532.2 & 13 & 23 & 62 & 59 \\
\hline
\end{tabular}

Table 3. Sulphur species (at.\% of total sulphur) for the unleached chalcopyrite, solvent-free at $148 \mathrm{~h}$ and $500 \mathrm{~h}$, and TCE20 at $218 \mathrm{~h}$ samples, derived from the $\mathrm{S} 2 \mathrm{p}_{3 / 2}$ spectra (Figs. 12c, h, m, r).

\begin{tabular}{|c|c|c|c|c|c|c|c|}
\hline \multirow{2}{*}{ Samples } & Properties & \multicolumn{6}{|c|}{$\mathrm{S}$ species } \\
\cline { 2 - 7 } & & $\mathrm{S}^{2-}$ & $\mathrm{S}_{2}{ }^{2-}$ & $\mathrm{S}_{\mathrm{n}}{ }^{2-}$ & $\mathrm{S}_{0}$ & $\mathrm{SO}_{3}{ }^{2-}$ & $\mathrm{SO}_{4}{ }^{2-}$ \\
\hline \multirow{3}{*}{$\begin{array}{c}\text { Unleached } \\
\text { chalcopyrite }\end{array}$} & Binding Energy (eV) & 161.1 & 161.9 & 163.2 & 164.4 & 165.5 & 168.9 \\
\cline { 2 - 8 } & FWHM (eV) & 0.7 & 1.2 & 1.9 & 1.3 & 1.3 & 1.3 \\
\cline { 2 - 8 } & at.\% & 13 & 22 & 30 & 12 & 9 & 14 \\
\hline \multirow{3}{*}{ Solvent-free 148 h h } & Binding Energy (eV) & 161.1 & 162.1 & 163.1 & 164.1 & - & 168.8 \\
\cline { 2 - 8 } & FWHM (eV) & 0.8 & 1.1 & 1.2 & 1.4 & - & 2 \\
\cline { 2 - 8 } Solvent-free 500 h h & at.\% & 8 & 37 & 21 & 23 & - & 11 \\
\cline { 2 - 8 } & Binding Energy (eV) & - & - & 163.1 & 164.1 & - & 168.7 \\
\cline { 2 - 8 } & FWHM (eV) & - & - & 1.3 & 1.3 & - & 1.4 \\
\hline \multirow{3}{*}{ TCE20 218 h } & at.\% & - & - & 1 & 3 & - & 96 \\
\cline { 2 - 8 } & Binding Energy (eV) & 160.9 & 162.2 & 163.4 & 164.2 & - & 168.7 \\
\cline { 2 - 8 } & FWHM (eV) & 0.8 & 1.2 & 1 & 1.1 & - & 1.4 \\
\cline { 2 - 7 } & at.\% & 3 & 4 & 39 & 5 & - & 49 \\
\hline
\end{tabular}

Table 4. Oxygen species (at.\% of total oxygen) for the unleached chalcopyrite, solvent-free at $148 \mathrm{~h}$ and $500 \mathrm{~h}$, and TCE20 at $218 \mathrm{~h}$ samples, derived from the $\mathrm{O} 1 \mathrm{~s}$ spectra (Figs. 12e, j, o, t).

\begin{tabular}{|c|c|c|c|c|c|c|}
\hline \multirow{2}{*}{ Samples } & Properties & \multicolumn{5}{|c|}{ O species } \\
\cline { 2 - 6 } & & $\mathrm{O}^{2-}$ & $\mathrm{OH} / \mathrm{SO}$ & $\begin{array}{c}\text { Chemisorbed } \\
\mathrm{H}_{2} \mathrm{O}\end{array}$ & $\begin{array}{c}\text { Physisorbed } \\
\mathrm{H}_{2} \mathrm{O}\end{array}$ & $\begin{array}{c}\text { Electrically- } \\
\text { isolated } \mathrm{H}_{2} \mathrm{O}\end{array}$ \\
\hline \multirow{3}{*}{$\begin{array}{c}\text { Unleached } \\
\text { chalcopyrite }\end{array}$} & Binding Energy (eV) & 529.9 & 531.4 & 532.1 & 533.1 & 534.8 \\
\cline { 2 - 7 } & FWHM (eV) & 1.5 & 1.5 & 1.5 & 1.5 & 2.3 \\
\cline { 2 - 7 } & at.\% & 2 & 9 & 30 & 13 & 46 \\
\hline \multirow{3}{*}{ Solvent-free 148 h } & Binding Energy (eV) & - & 531.4 & 532.3 & 533.4 & 534.4 \\
\cline { 2 - 7 } & FWHM (eV) & - & 1.5 & 1.5 & 1.5 & 1.5 \\
\cline { 2 - 7 } & at.\% & - & 16 & 33 & 30 & 21 \\
\hline \multirow{3}{*}{ Solvent-free 500 h } & Binding Energy (eV) & - & 531.4 & 532.0 & 533.1 & 534.0 \\
\cline { 2 - 7 } & FWHM (eV) & - & 1.5 & 1.5 & 1.5 & 1.5 \\
\cline { 2 - 7 } TCE20 218 h & at.\% & - & 44 & 44 & 10 & 2 \\
\cline { 2 - 6 } & Binding Energy (eV) & - & 531.4 & 532.0 & 532.9 & 534.1 \\
\cline { 2 - 6 } & FWHM (eV) & - & 1.5 & 1.5 & 1.5 & 1.5 \\
\hline
\end{tabular}



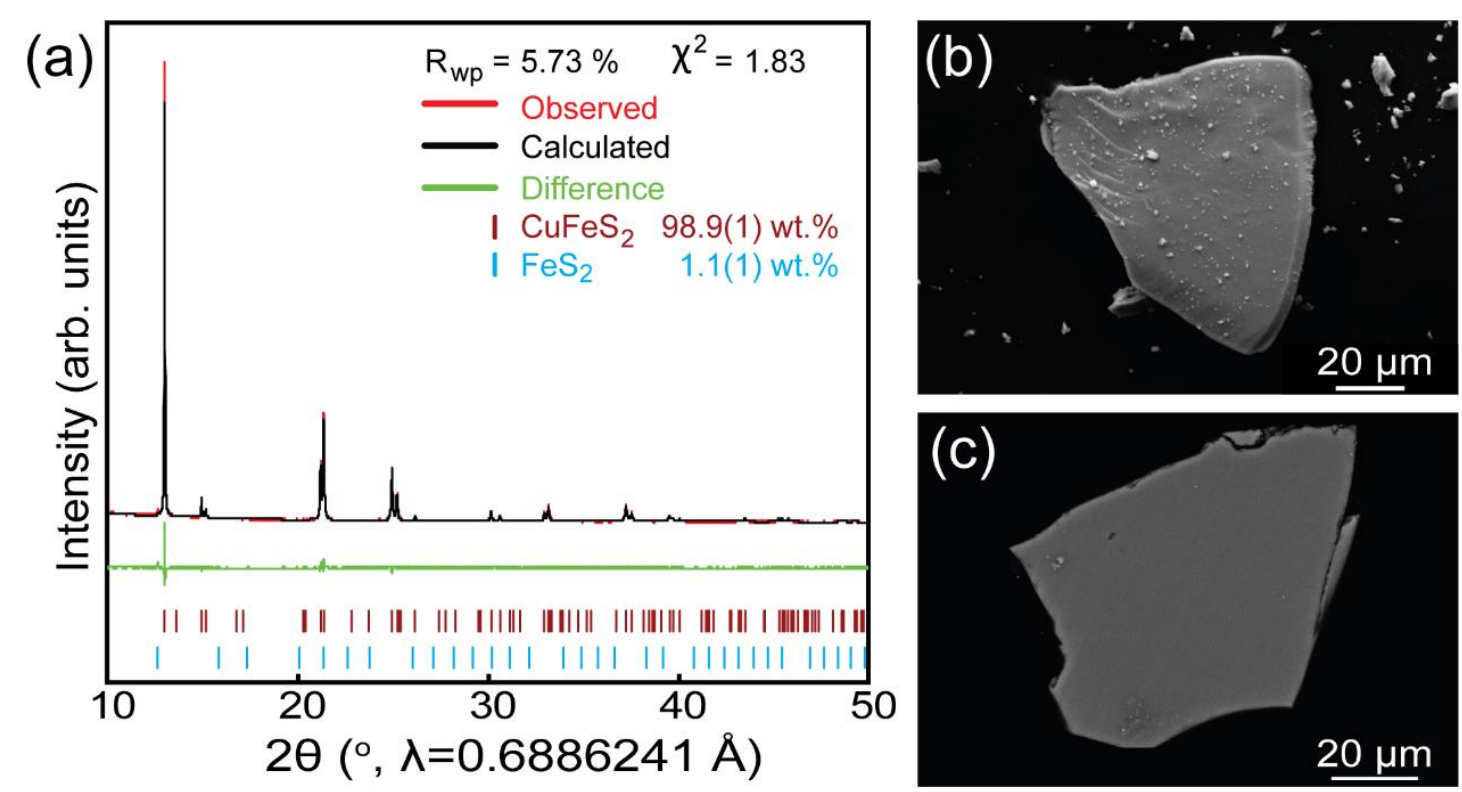

Fig. 1. The starting chalcopyrite. (a) PXRD pattern with Rietveld analysis; the red and black patterns are the data and calculated pattern respectively, while the green line shows the difference between the data and the calculated pattern; the vertical lines shows the Bragg positions of chalcopyrite (brown) and pyrite (blue); Rwp and $\chi^{2}$ are criteria of the fitting quality. The weight percentage of the phases are obtained from the fitting. (b) SE image of a typical grain, and (c) BSE image of the cross-section of a typical grain.

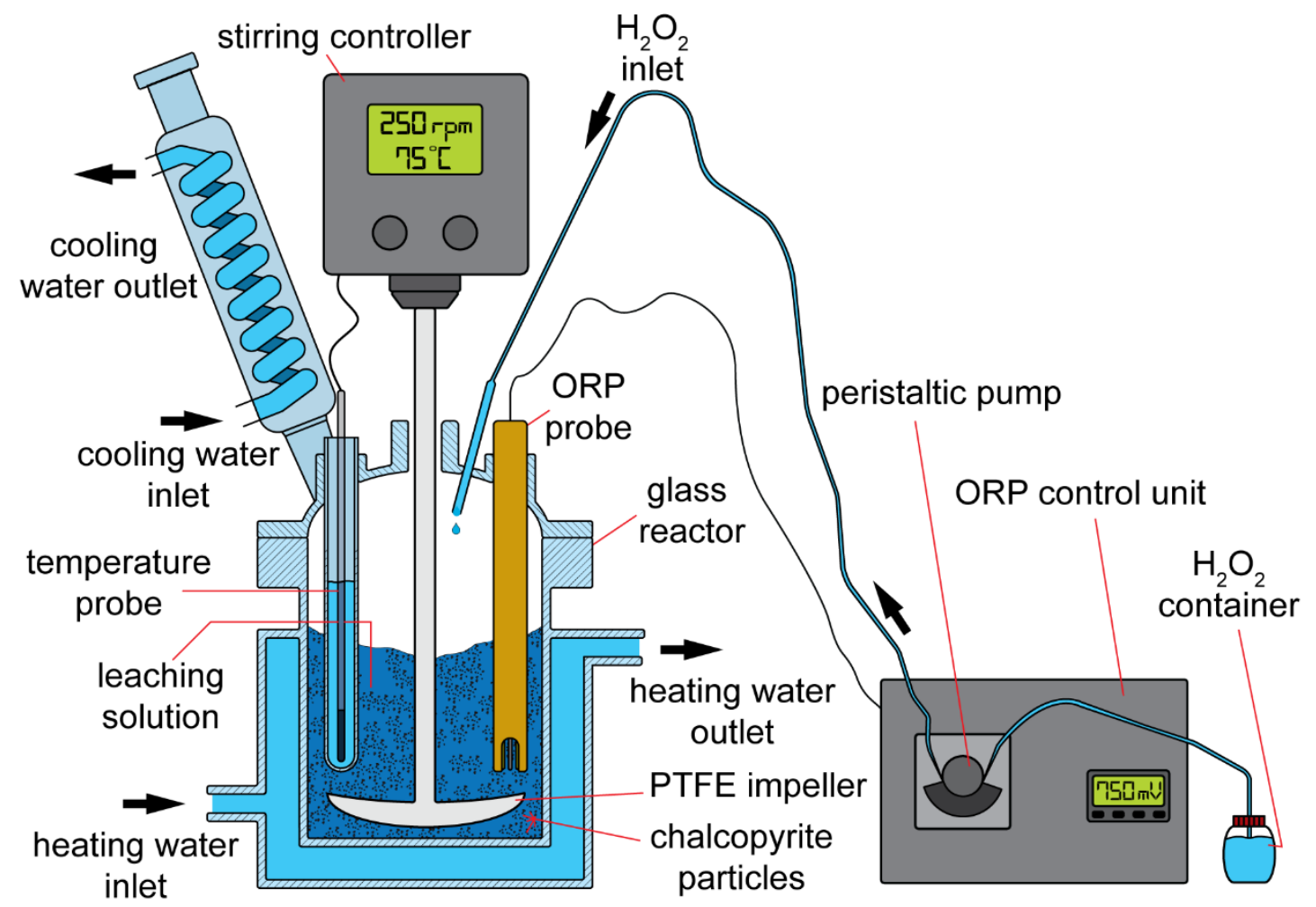

Fig. 2. Schematic illustration of the leaching reactor. 


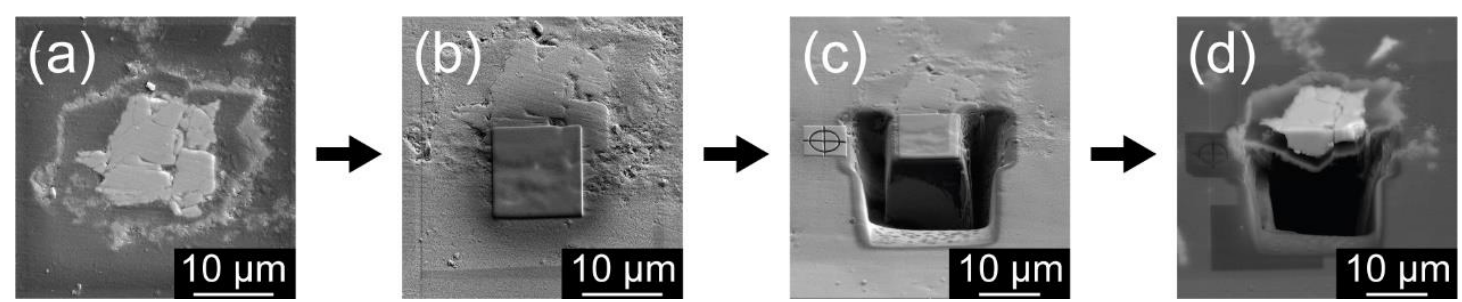

Fig. 3. The procedure of FIB-FESEM tomography slice and view analysis: (a) a representative particle is embedded into an epoxy resin block and polished, (b) a $200 \mathrm{~nm}$ Pt layer was ion beam deposited over the region of interest, (c) removal of the surrounding material, and (d) serial slice by FIB and image by SEM for approximately 200 slices.
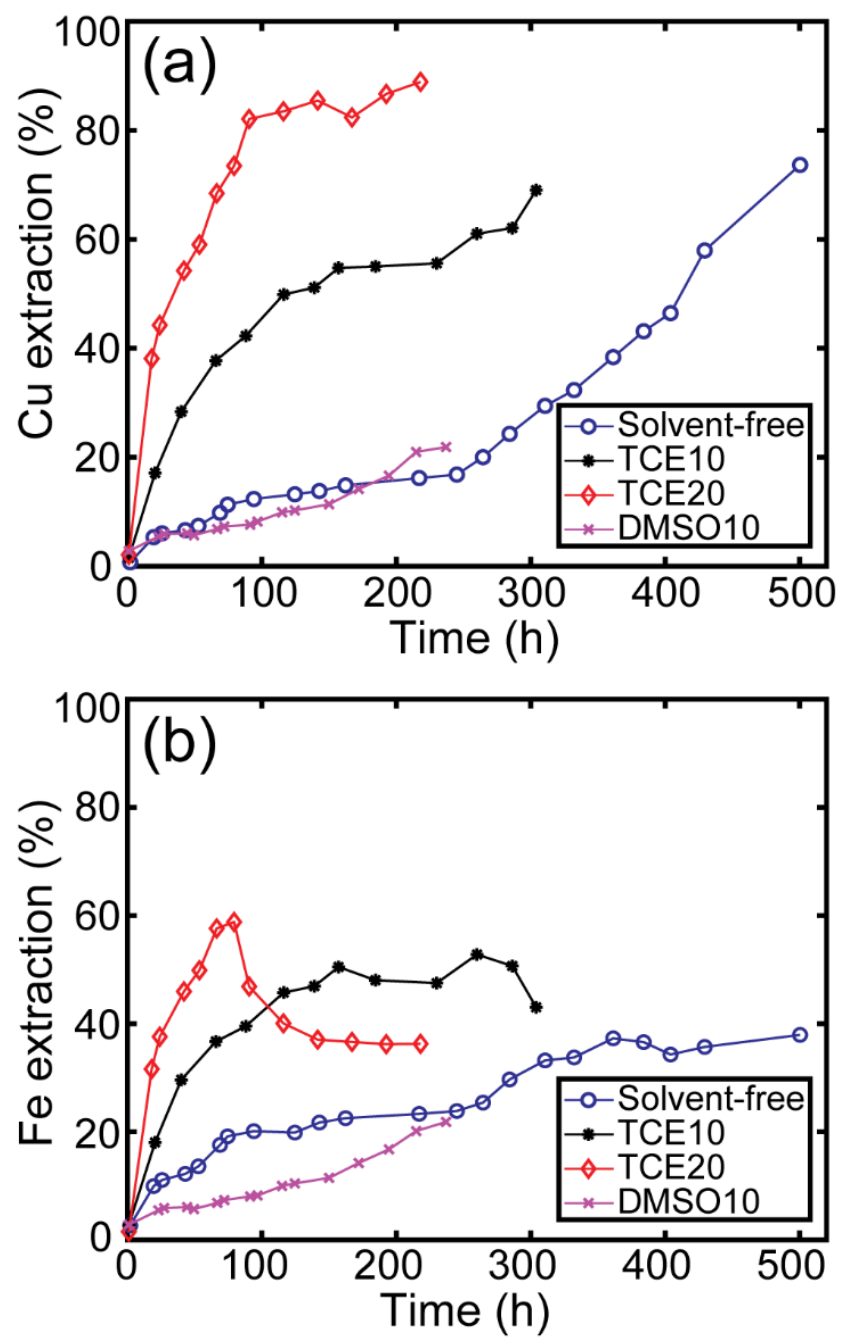

Fig. 4. (a) $\mathrm{Cu}$ and (b) Fe extraction (\%) as a function of leaching time for the four leaching experiments. 

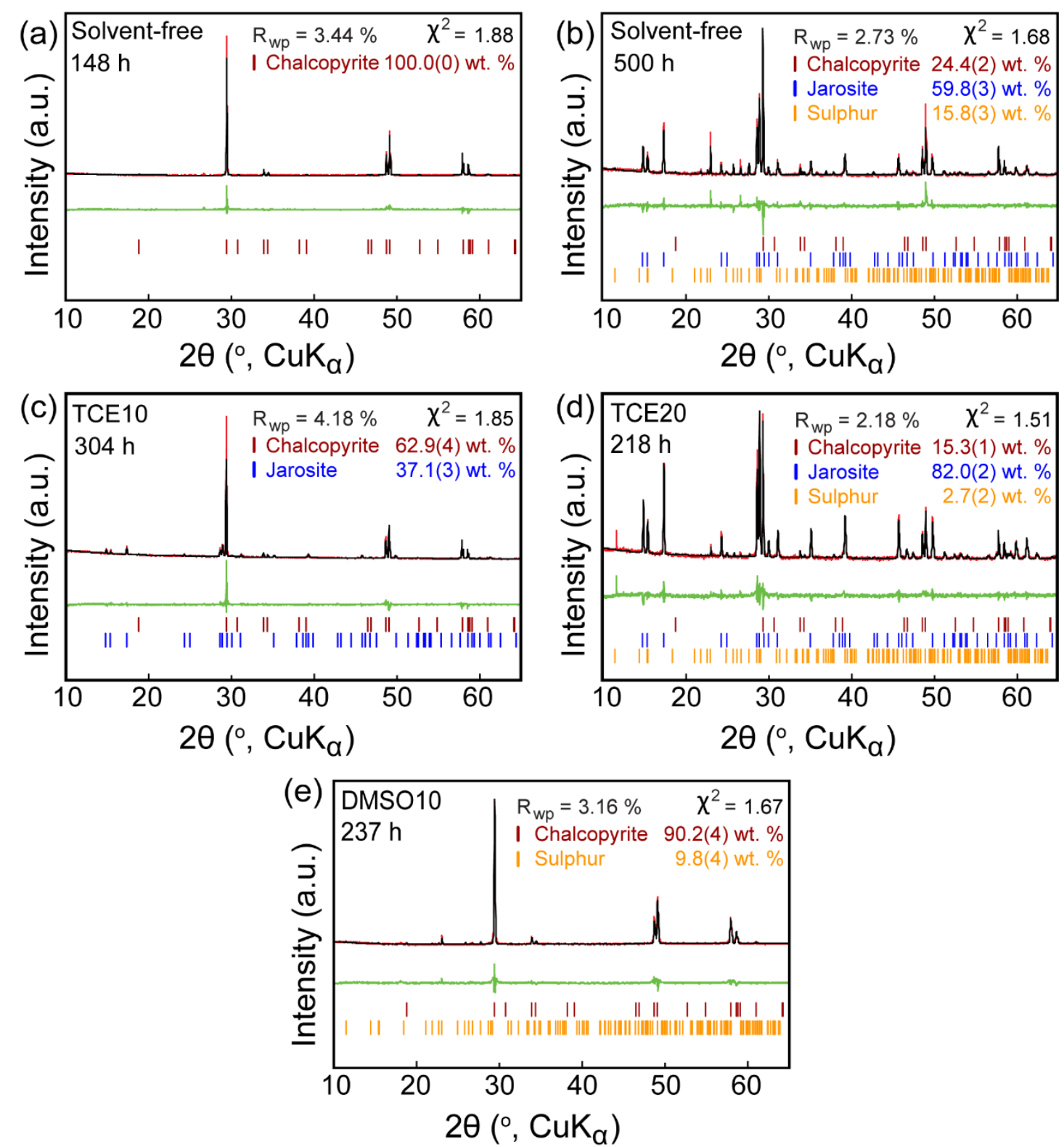

Fig. 5. PXRD patterns and quantitative phase analyses of leached residues. (a) solvent-free at $148 \mathrm{~h}$, (b) solvent-free at $500 \mathrm{~h}$, (c) TCE10 at $304 \mathrm{~h},(\mathrm{~d}) \mathrm{TCE} 20$ at $218 \mathrm{~h}$, and (e) DMSO10 at $237 \mathrm{~h}$. Rietveld refinement metrics and results are in the inset of each pattern. See Fig. 1 caption for more explanations. 

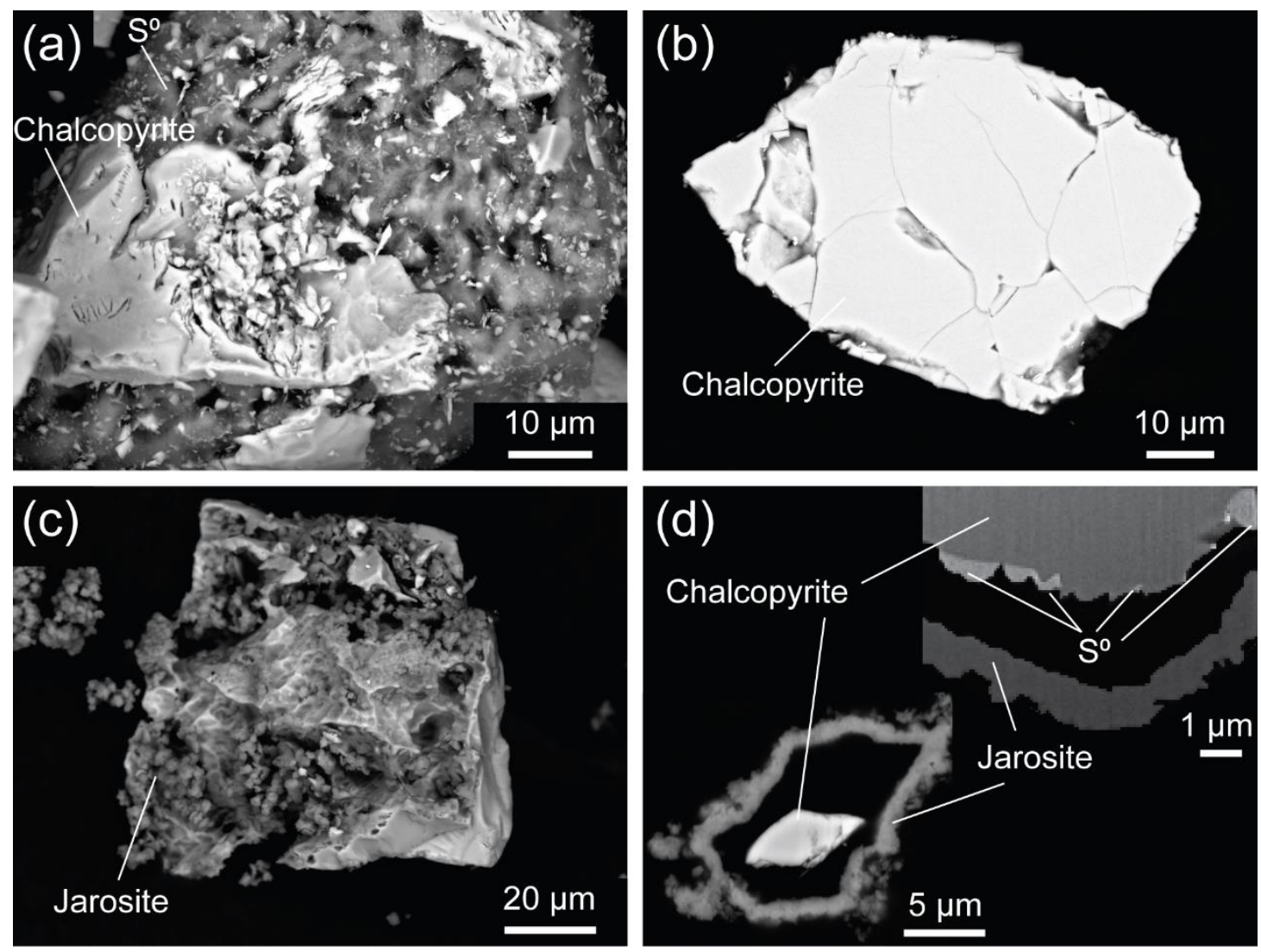

Fig. 6. BSE images of the leached chalcopyrite residues in the solvent-free experiments. (a) grain surface after $148 \mathrm{~h}$, (b) grain cross-section after $148 \mathrm{~h}$, (c) grain surface after $500 \mathrm{~h}$, and (d) grain cross-section after $500 \mathrm{~h}$.
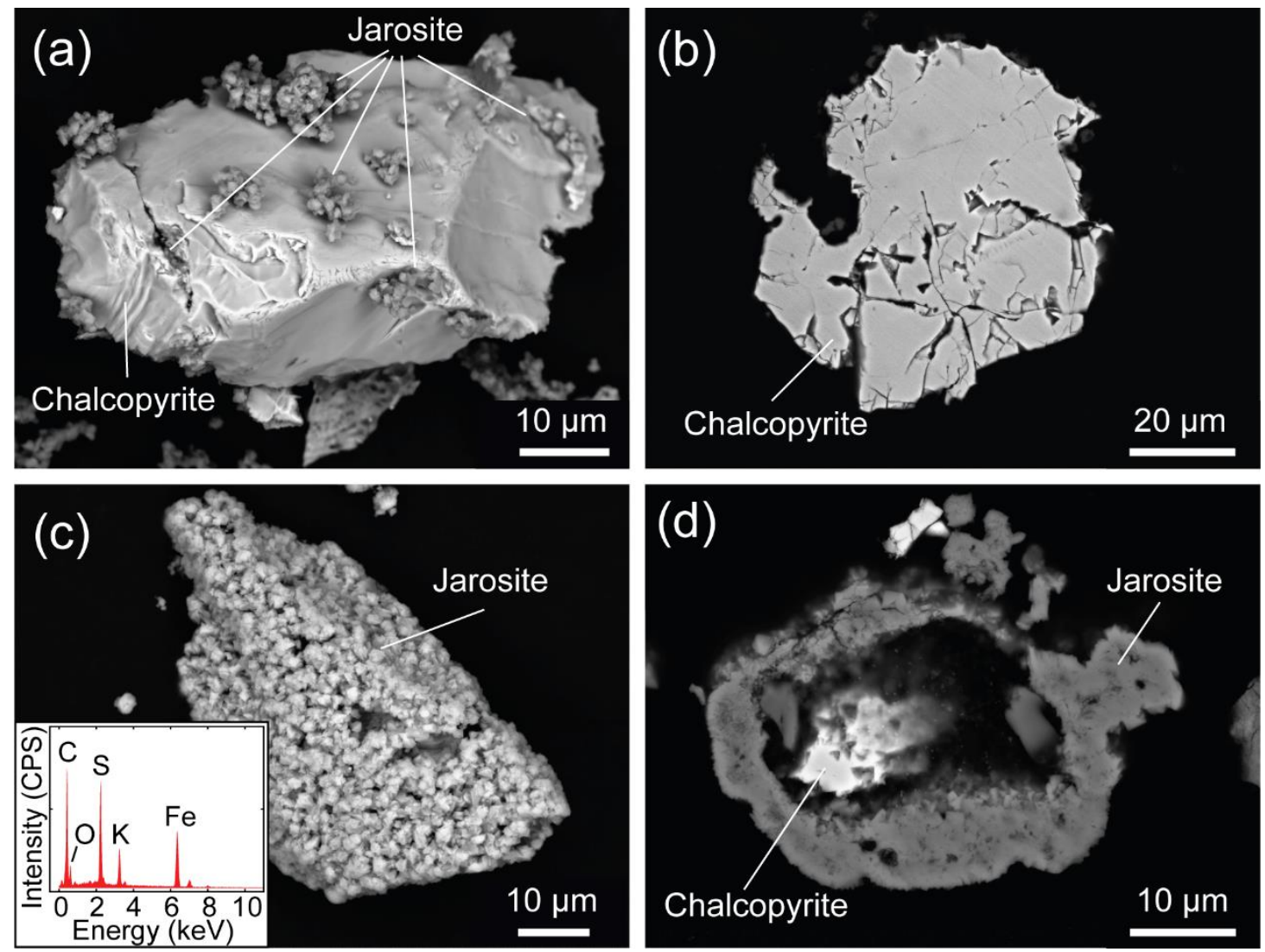

Fig. 7. BSE images of the leached chalcopyrite residues in the TCE10 experiments. (a) grain surface after $116 \mathrm{~h}$, (b) grain cross-section after $116 \mathrm{~h}$, (c) grain surface after $304 \mathrm{~h}$, and (d) grain cross-section after $304 \mathrm{~h}$. 

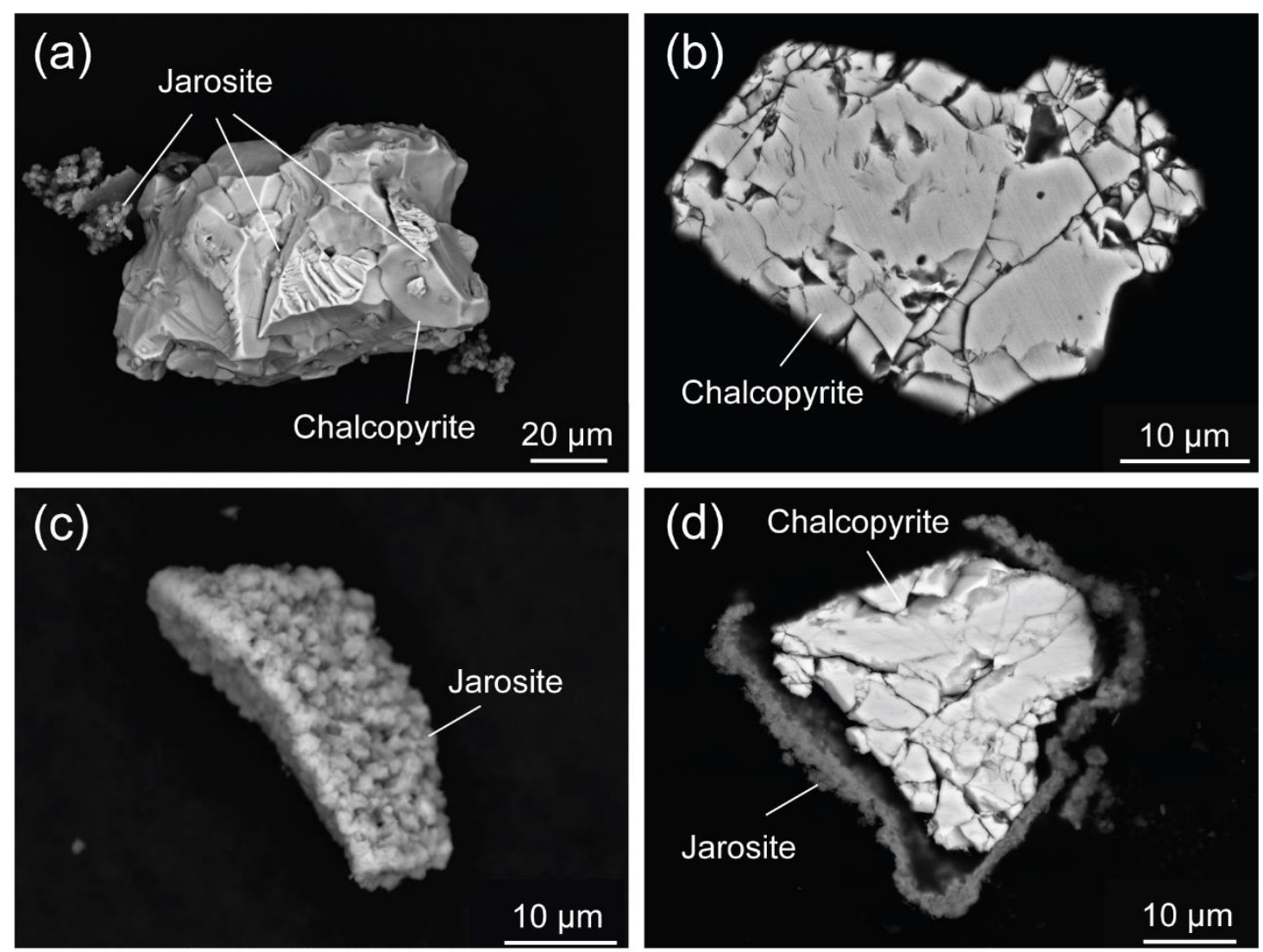

Fig. 8. BSE images of the leached chalcopyrite residues in the TCE20 experiments. (a) grain surface after $90 \mathrm{~h}$, (b) grain cross-section after $90 \mathrm{~h}$, (c) grain surface after $218 \mathrm{~h}$, and (d) grain cross-section after $218 \mathrm{~h}$.
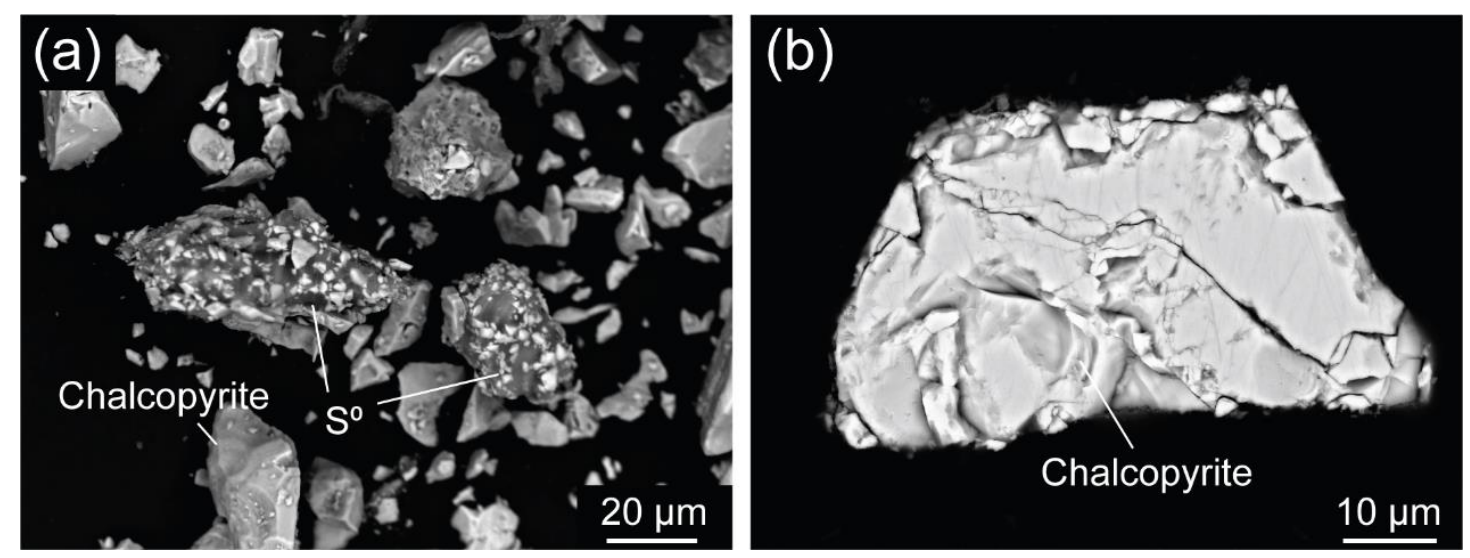

Fig. 9. BSE images of the leached chalcopyrite residues after $90 \mathrm{~h}$ in the DMSO10 experiment, showing (a) grain surface and (b) grain cross-section. 
(a) Jarosite layer, solvent-free, $500 \mathrm{~h}$
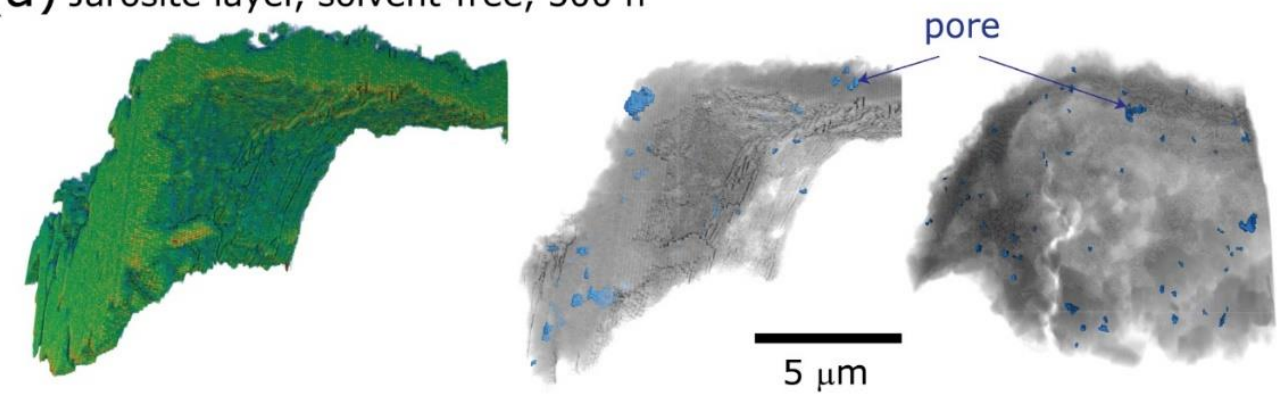

(b) Jarosite layer, TCE20, $218 \mathrm{~h}$

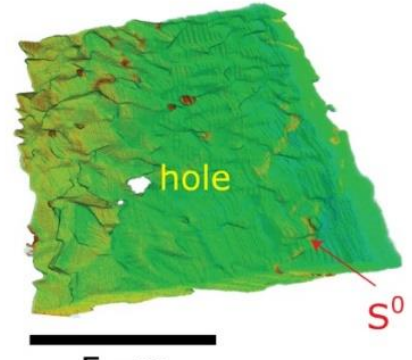

$5 \mu \mathrm{m}$
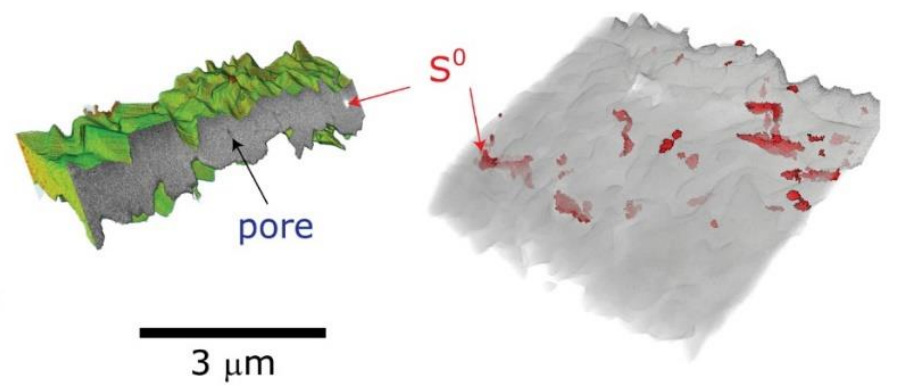

Fig. 10. FIB-SEM tomography data of jarosite shells from (a) solvent-free experiment at $500 \mathrm{~h}$, showing porosity, and (b) TCE20 experiment at $218 \mathrm{~h}$, showing holes and embedded sulphur. The green-yellow-red and grey coloured isosurfaces represent the outer and inner surfaces of the jarosite shell. The grey colour is semi-transparent to reveal the pores (a) and embedded sulphur (b) in jarosite. Also see videos of these 3D reconstructions in the supporting information.

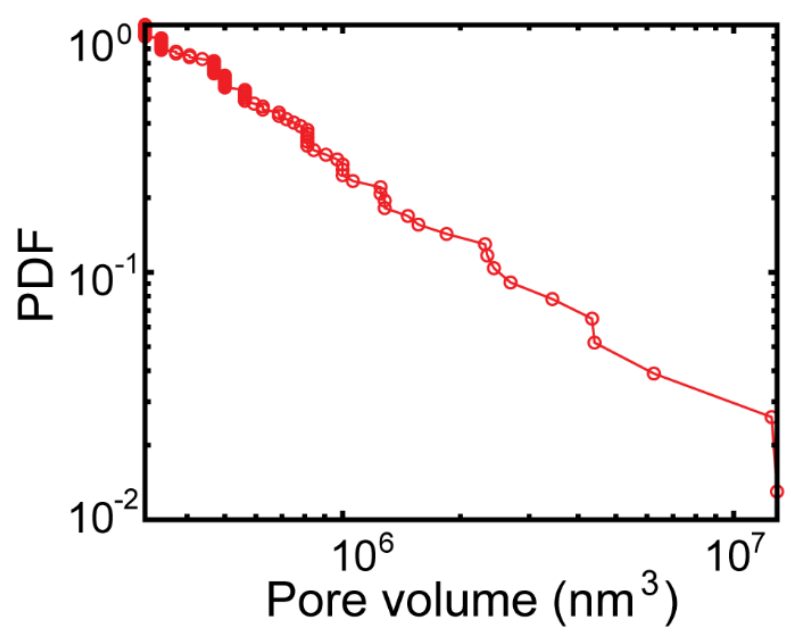

Fig. 11. Pore volume probability distribution function (PDF) measured using 3D tomographic analysis shown in Fig. 10a obtained from the jarosite layer of the sample leached in solvent-free experiment at $500 \mathrm{~h}$. 

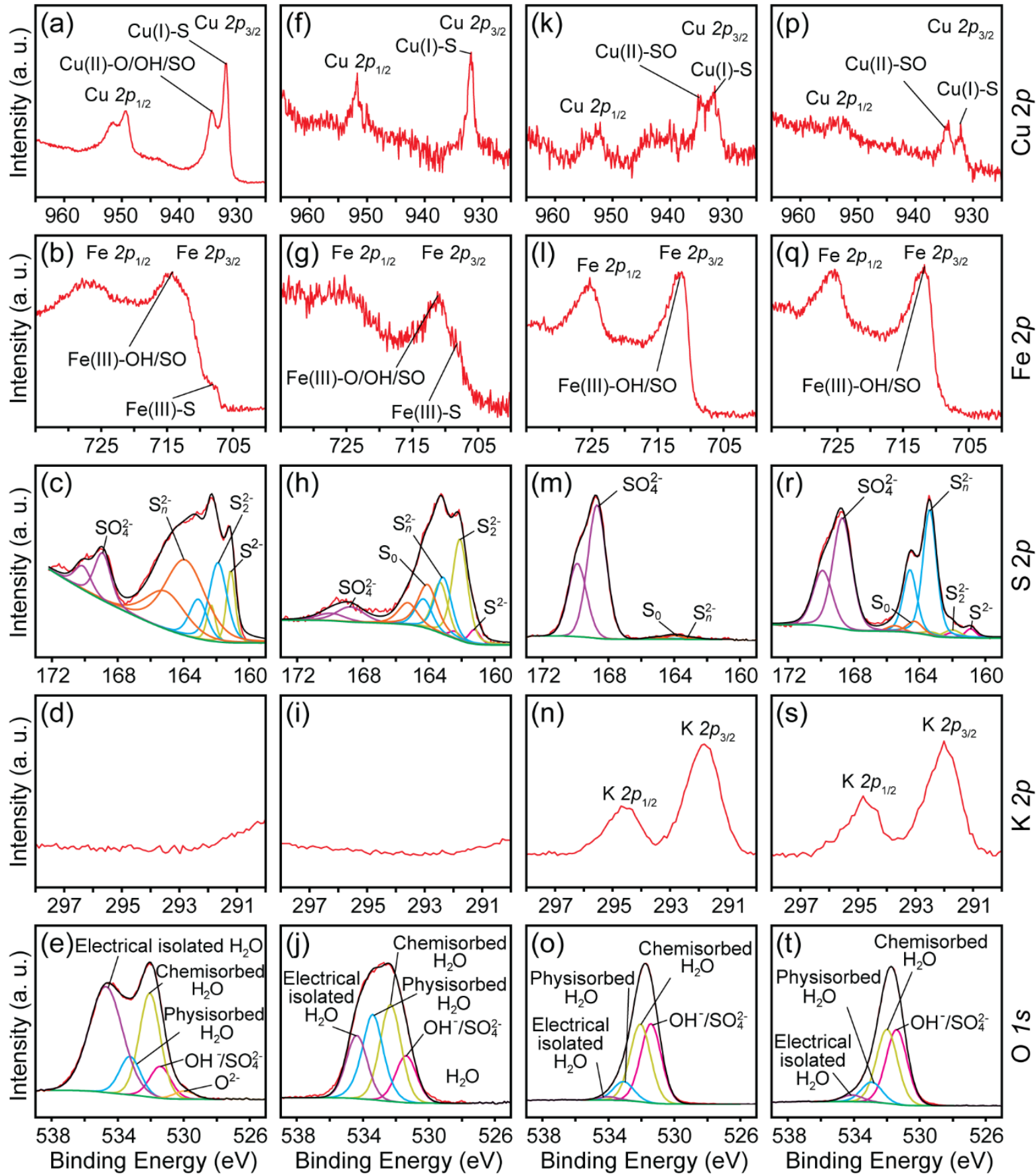

Fig. 12. XPS spectra showing $\mathrm{Cu} 2 p, \mathrm{Fe} 2 \mathrm{p}, \mathrm{S} 2 \mathrm{p}, \mathrm{K} 2 \mathrm{p}$ and $\mathrm{O}$ 1s peaks from the surface of samples collected from: (ae) unleached chalcopyrite, (f-j) solvent-free experiment at $148 \mathrm{~h},(\mathrm{k}-\mathrm{o})$ solvent-free experiment at $500 \mathrm{~h}$, and (p-t) TCE20 experiment at $218 \mathrm{~h}$. 

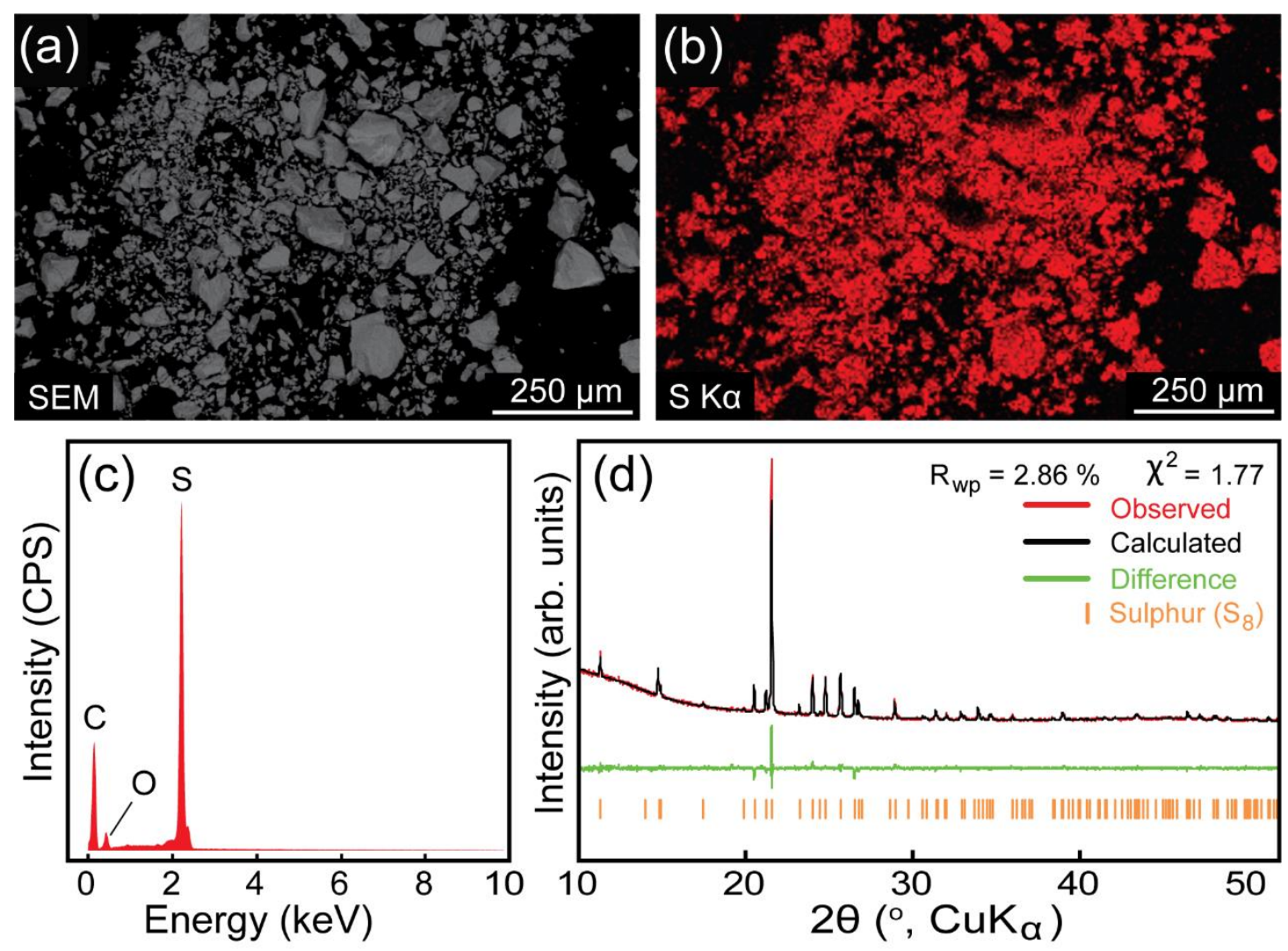

Fig. 13. (a) SEM image, (b) elemental EDS-map, (c) EDS spectra, and (d) PXRD pattern of extracted sulphur by TCE from TCE20 experiment at $218 \mathrm{~h}$. Rietveld refinement metrics and results are in the inset of each pattern. See Fig. 1 caption for more explanations. 

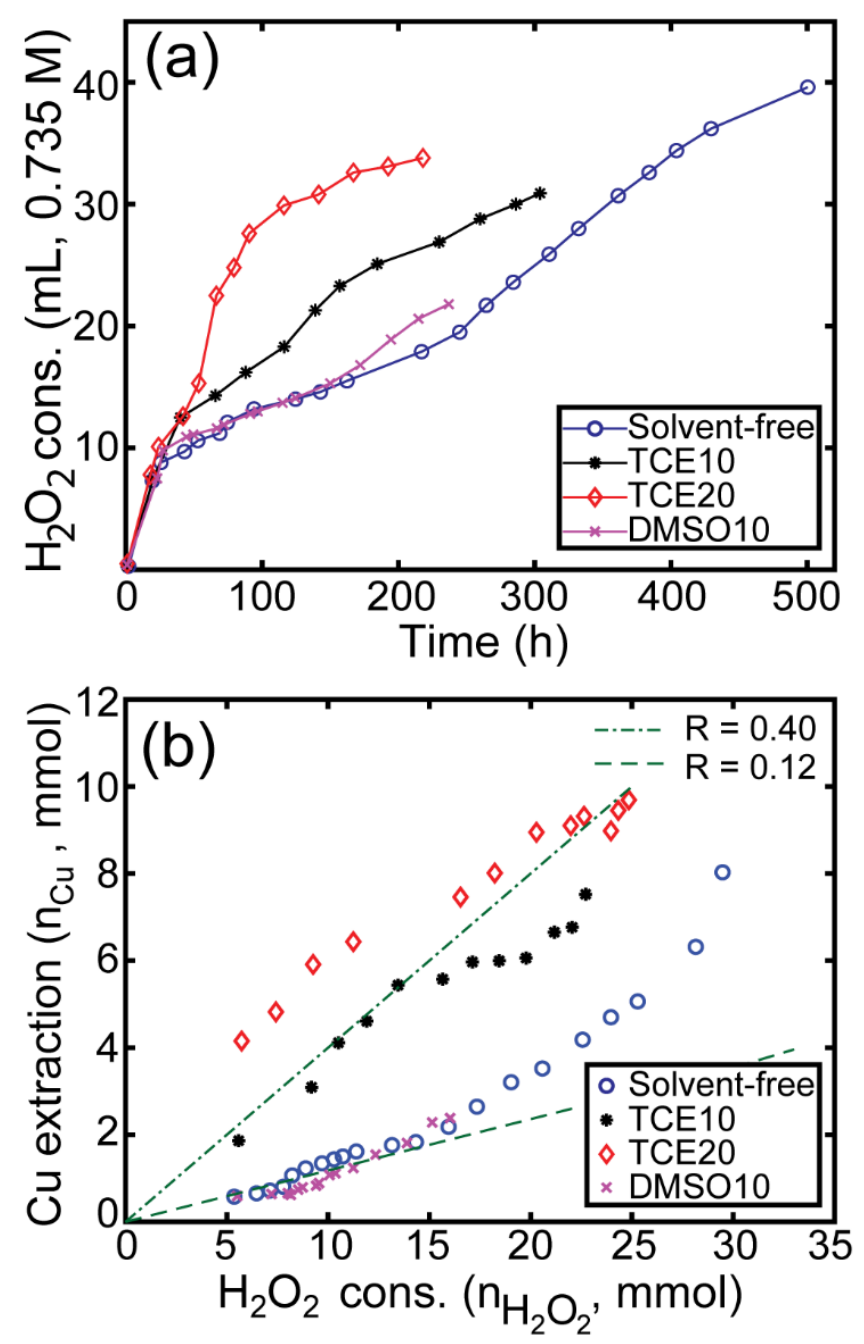

Fig. 14. (a) The consumption of hydrogen peroxide with reaction time, and (b) copper extraction (mmol) as a function of hydrogen peroxide consumption ( $\mathrm{mmol}$ ). The linear lines with slopes $\mathrm{R}=0.40$ and $\mathrm{R}=0.12$ correspond to the overall reactions assuming sulphate and elemental sulphur are the final oxidised forms of $\mathrm{S}$ (see Reactions 1 and 2 and more descriptions in the text).

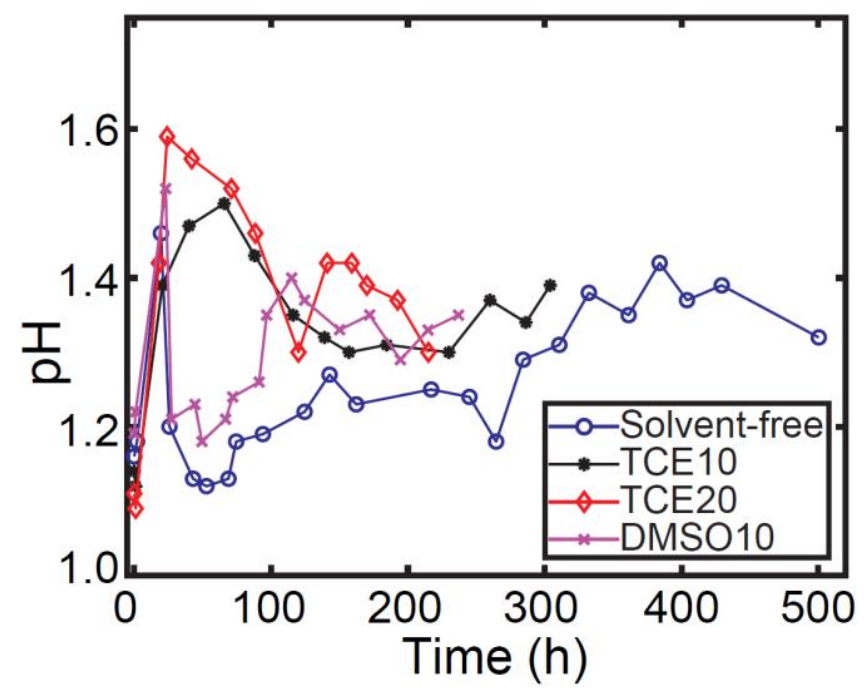

Fig. 15. The change of $\mathrm{pH}$ as a function of leaching time for the four leaching experiments. 


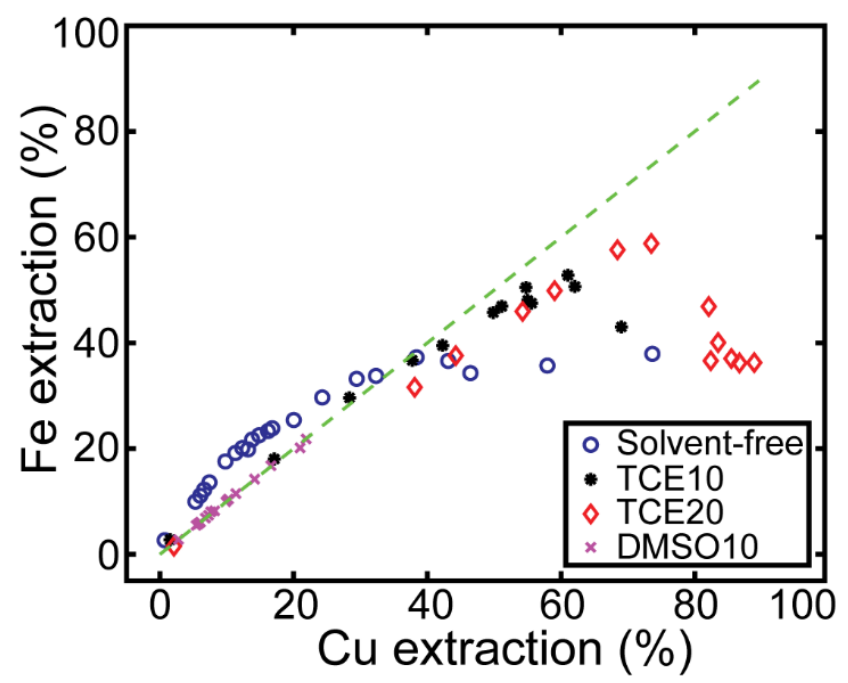

Fig. 16. Comparison of the extractions of $\mathrm{Fe}$ and $\mathrm{Cu}$. The linear dash line means equimolar extraction of $\mathrm{Fe}$ and $\mathrm{Cu}$. 

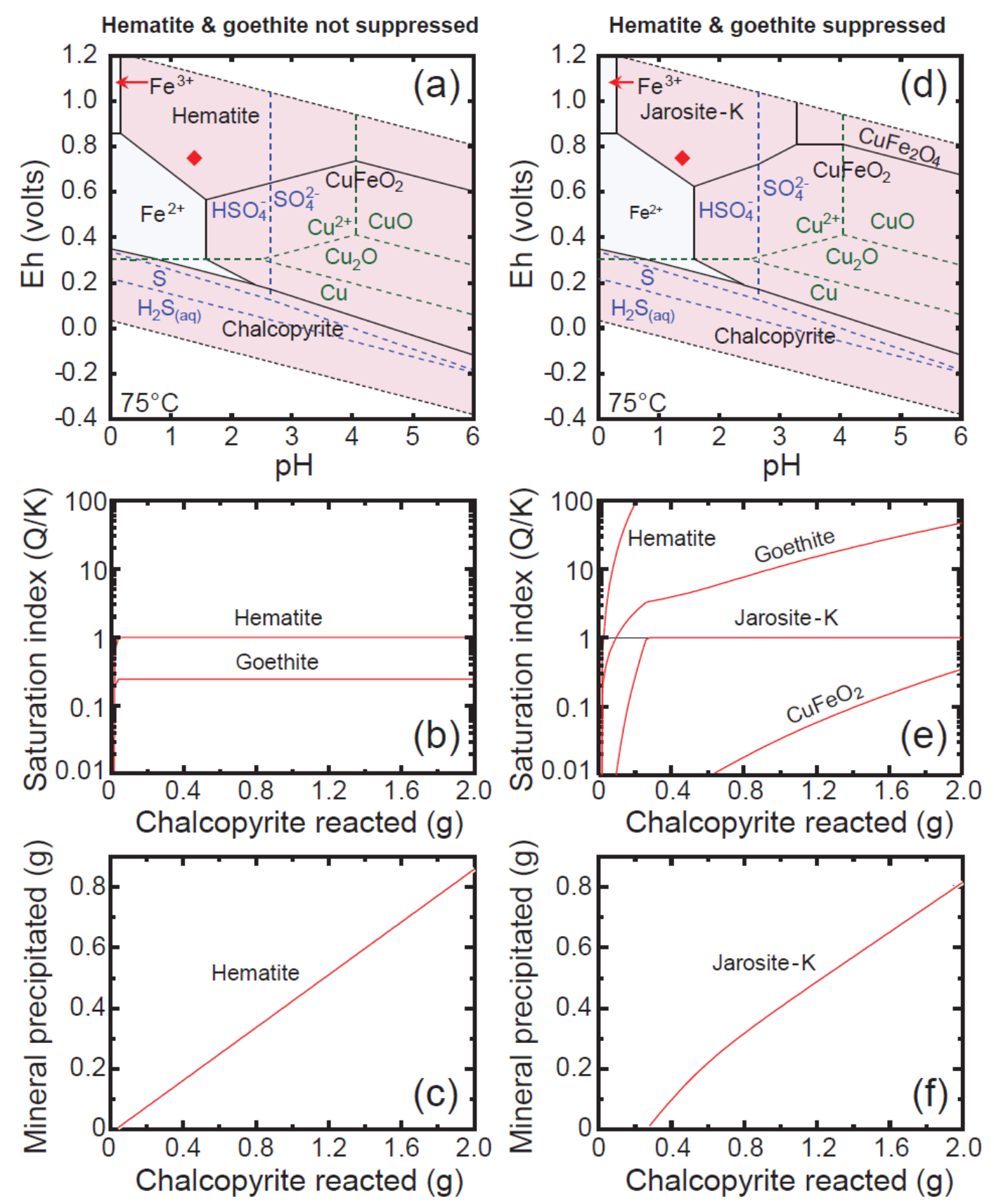

Fig. 17. Thermodynamic analyses of the chalcopyrite leaching experiment at $75{ }^{\circ} \mathrm{C}$, comparing the conditions when hematite and goethite are not suppressed (a-c) and suppressed (d-f) in the modelling. (a, d) Eh-pH predominance diagram of the Fe-Cu-S-O system at $75{ }^{\circ} \mathrm{C}$. Dashed lines show the sub-diagrams of sulphur (blue) and copper (green). The concentrations of ions are equivalent to $40 \%$ leaching of chalcopyrite in the solvent-free experiment: $\sum \mathrm{Fe}=0.00872 \mathrm{M}$, $\sum \mathrm{Cu}=0.00872 \mathrm{M}, \sum \mathrm{S}=0.06744 \mathrm{M},\left[\mathrm{K}^{+}\right]=0.001304 \mathrm{M}$, and $\left[\mathrm{Na}^{+}\right]=0.002492 \mathrm{M}$. The position of the red diamond means the leaching condition of this study. (b, e) Numerical modelling of chalcopyrite leaching, showing the saturation indexes of minerals. The starting solution composition is the same as the solvent-free experiment. This solution is progressively reacted with $2 \mathrm{~g}$ of chalcopyrite containing $1.63 \mathrm{mmol} \mathrm{K}^{+}$and $3.11 \mathrm{mmol} \mathrm{Na}^{+}$at fixed $\mathrm{Eh}$ at $750 \mathrm{mV}$. (c, f) Mineral precipitation as a function of reacted chalcopyrite. 


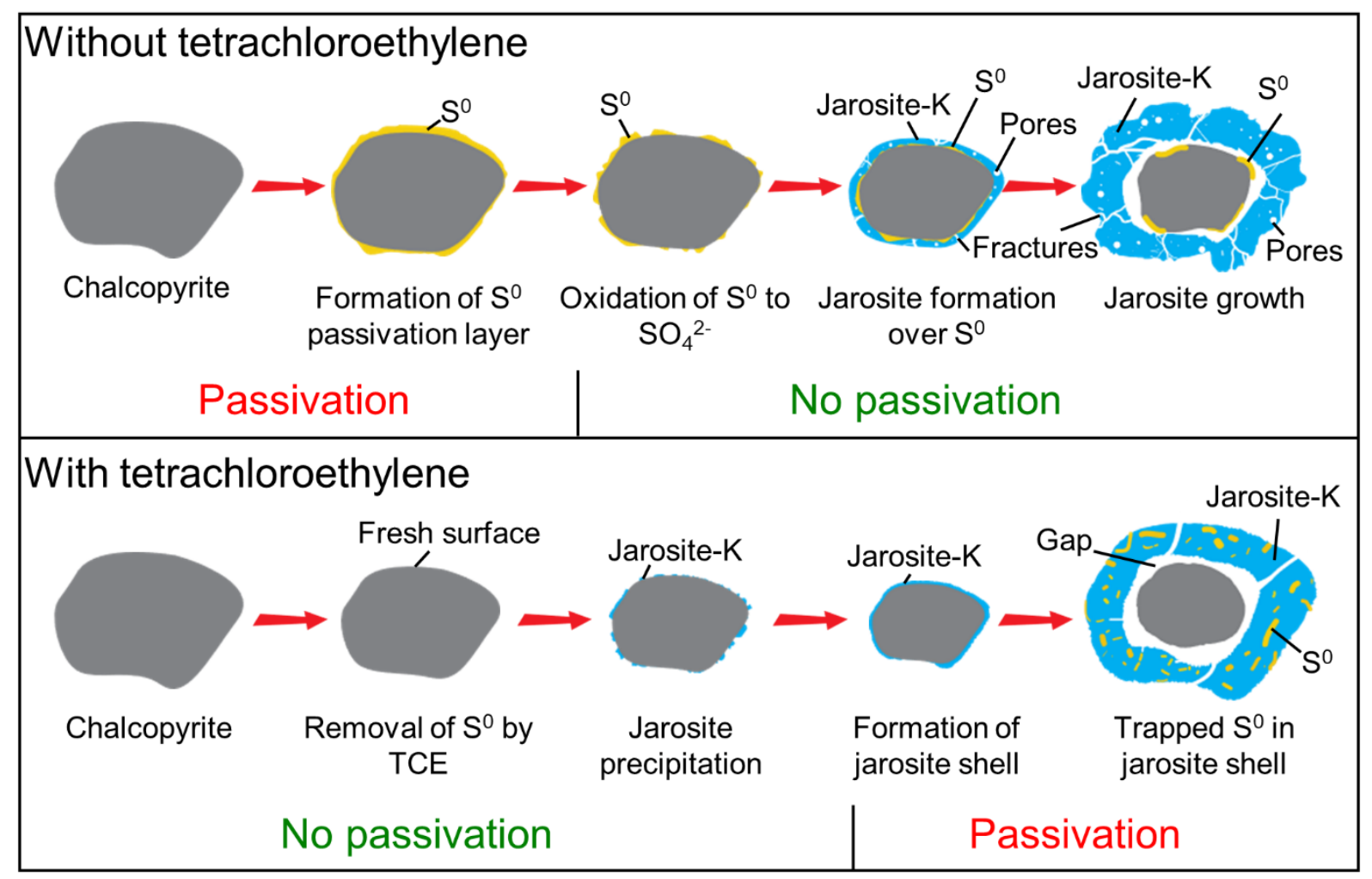

Fig. 18. The proposed mechanisms of chalcopyrite leaching with and without tetrachloroethylene. Condition: $75{ }^{\circ} \mathrm{C}$, $750 \mathrm{mV}, 0.05 \mathrm{M}$ sulphuric acid solution, and slurry density of $4 \mathrm{~g} \mathrm{~L}^{-1}$. 